\title{
EXCLUSION-LIST METHODOLOGY FOR WEATHERIZATION PROGRAM IN THE PACIFIC NORTHWEST
}

A.V. Hero, I. Turiel, W.J. Fisk, J.R. Gimman, and C.W. Traynor

\author{
Buflding Ventilation and Indoor Afr Quality Program \\ Energy and Environment Division \\ Lawrence Berkeley Laboratory . \\ University of Cajifornia \\ Berkeley, CA 94720
}

May 1982

Th1s work was supported by the Assistant Secretary for Conservation and Renewable Energy, offlce of Buflding Energy Research and Development, Bullding Systems DIvision of the U.S. Department of Energy under Contract No. DE-ACO3-76SF00098, and by the Bonneville Fower Administration (Philip W. Thor, project manager) P.0. Box 3621, Portland, Oregon, 97208. 
TABLE OF CONTEHTS

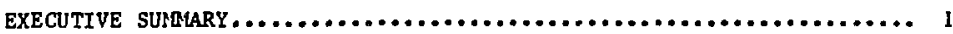

PART I. INFILTRATION REDUCTION, INTOOR POLLUTION, AND

CONTROL NEASURES........................ 5

1. BPA Weatherization Program............................. 6

A. Weatherization Measures............................. 6

B. Ilousing Characteristics............................. 7

C. Infiltration Rate Reduct Ion from Weatherization............ 7

2. Indoor Alr Pollutant Sources, Concentrations, and Health Effects........................... 12

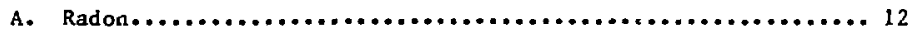

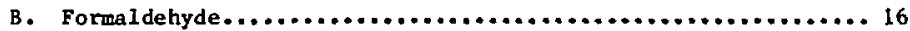

C. Combustion Products.................................. 19

D. Other Pollutants.................................... 25

3. Indoor Afr Qual1ty Control Techniques..................... 3I

A. Introduction..................................... 31

B. Source Control.................................... 31

C. Vent1lation Control Techniques....................... 33

D. Alr Cleaning Control Techniques....................... 36

E. Discussiton of Control Techniques.................... 40

PART II. DEVELOPLENT OF A IETIODOLOCY FOR ALTERING THE EXCLUSION IIST......................47

4. Concentration Distributions In Excluded Housing Classes and the Effect of Infiltration Reductior.........................49

A. Radon Exclusion Classes..............................49

B. Wood Stoves and Unvented Combustion Appliances........... 56

C. Urea-Formaldehyde Insulation and Other Formaldehyde Sources.. 57 
5. Cenerfc Considerations in Altering the Exclusion List.......... 59

A. Requirements for Removing Classes from Exclusion List....... 59

B. Adding Classes to the Exclusion List......................61

C. Risk, Standards, and Responsib1l1ty................... 63

6. Methodology for Altering the Exclusion List................66

A. Radon Exclustons.................................. 66

B. Wood Stove. and Unvented Combustion Appliances..............71

C. Urea-FormaIdehyde Insulation and other Formaldehyde Sources.. 74

D. Other Excluded Homes.............................. 75

E. General Notes.................................... 76

Appendix A - Health Standards and Guldelines................... 79

Appendix B - A Model for Estimating the Effect of

Control Techafques.........................85

Addendum - Formulation of Present Crfteria for Incluston of Infiltration-Reduction Measures in the Regional Weatherization Program, prepared by Don Wolfe, Bonneville Power Adnt: stracton...................... B7 
Background

During 1981 the Bonneville Power Administration (BPA) began 1ts Regional Weacherization Frogram, offering financlal incentives that encourage mcasures to reduce electricicy use in homes. Because significant concentrations of alrborne pollutants are of cen present in residential bulldings, BPA considered explicitly the Impacts on occupants' health that could arise from weatherization measures that reduce alr infiltration rates and thereby ralse levels of Indoor-generated pollutants. As discussed in an Environmental Assessuent as revised in September 1981 and in an addendum prepared for this document, the Progran was designed to pernit the full array of weatherization measures only in houses meeting criteria indicating that "major sources of indoor air pollutants are minimized". Infiltration-reducing measures would not be offered to homes falling these criteria, thereby avolding potentlai increases in Indoor pollutant levels and assuring that the Program has no significant adverse effects on the quality of the human environment.

Several classes of pollutants are known to reach potentfally harmful levels in sone residences: radon and its daughters, arising from the ground, bullding materials, or household water; combustion products, from unvented or wood-burnling applfances; and formcldehyde and other organics, from buliding materials or furnfshings. Radon concentrations vary over a factor of a thousand in U.S. homes, with a stmilar range in the BPA area. Continued exposure to radon (and Its daughters) is presumed to cause an added fisk of lung cancer that is proportional to the concentration, and the higher concentrations pose a substantial risk to occupants. Relatively few unvented applisnces are present in the homes offered the program, but many of the homes contain wood-burning heating appliances, from which a wide array of pollutants are emitted, of ten causing afrborne concentrations comparable to outdoor air quality standards. Among formaldehyde-enttting materlals, urea-formaldehyde (UF) foam Insulation is the most notable since - if the material is foproperly installed -- Indoor formaldehyde concentrations can become high enough to cause acute distress to occupants. Ordinary infiltration-reducing measures, such as those offered in the Regional Weatherization Progran, can be expected to increase Indoor pollutant concentrations by about $30 \%$ on the average, a signfficant change if levels are already high.

The five criterfa set forth in the Environmental Assessment assure that Infittration-reducing measures are offered only for houses with features that minfmize the sources just mentioned: radon sources are minimfzed by use of ventilated crawlspaces, wood-frame construction (with little interlor masonry), and municlpal water supplies; combustion products are minimized by the abserce of unvented combustion appliances or wood-burning stoves; and formaldehyde is minimized by the absence of UF foam Insulation. Although the alternative of offerfing infiltrationreducing measures in conjunction with measures for mitigating potentlally adverse effects on air quality was considered, the adequacy of such measures was not thought to be assured. 
Since infiltration-reducing measures are among the more effective ways of reducing residential energy use, BPA continues to be interested in reducing the number of houses from which these measures are withheld. Th1s document sets forth a strategy for offering these measures to more homes without significantly affecting the quality of the human environment. At a Iater date, an Environmental Impact Statement w111 be completed, assessing the impacts of a program containing infiltrationreducing measures. In addition, BPA and other entities are supporting research on indoor afr pollutants, including monttoring and control techniques, as well as strategles for applying them.

Hethodology for Altertng the Exclusion List

The list of housing classes from which finflitration-reducing measures are excluded could be altered on the basts of several different considerations: (1) Present knowledge of Indoor pollutant sources and concentrations and of infiltration-reduction may indicate that the exclusion list could be altered, In certain respects, with no significant impact. Related to this is the possibility (2) that the weatherization program could include new elements that are adequate to assure no significant impact. (3) The weatherization program nay be followed by programs or determinations that have the same effect as such elements. These approaches contain three essential asper.ts: (1) development of better infocmation on sources and concentrations in varlous housing classes; (2) adoption of criteria on "significant" changes in individual or average Indoor exposures to pollutants; and (3) Implementation of mitigation measures, elther concurrently or retrospectively, in houses requiring them.

Because the objective of changing the exclusion Iist is to reduce the number of houses restricted from infiltration-reducing measures, emphasis is given to the radon and wood-stove exclusion classes, each of which contain as many as half of otherwise qualifying houses. Even for the first of tnese, an examination of the factors affecting the radon entry rate (or source "magnitude") Indicates that alteration of the radon exclusion criteria to reduce the number of houses may amount to a reformulation of the criteria, racher than simple removal from the $11 \mathrm{st}$. lorecver, in considering other possible changes to the exclusion IIst, indication is given, not only of classes of houses that have a potential for removal of the exclusion, but also -- for the sake of consistency -of classes that might be added to the exclusion list on the basis of similar considerations. For example, although the general UF-foam exclusion ought be removed if monttoring is perfonmed to assure low formaldehyde levels, similar monttoring wight be required in homes with substantial amounts of other formaldehyde sources.

Radon and Wood-Stove Exclusions

Reducing the number of radon-excluded houses can be accomplished by measuring indoor radon levels or by characterizing radon sources, elcher of which can usefully be linked to characterization of geographic areas for their radon (source) potentlal. Ceographic characterization is highly significant because the main radon source is usually the ground on which a house is bullt, and a house's radon entry rate charefore 
depends ultimately on the strength of this source, as well as characteristics of the house understructure, which is the factor now considered by the excluston 11st. Reorienting the radon exclusions around characterization of radon sources by area, using indoor measurements or -- even better -- wide-scale aerial radionetric survey data that are already avallable, couid provide an efficlent strategy for determining where the radon exclusion should be retafned, while permitting infiltration-reduction in other areas. This strategy would also have the benefit of Identifying areas having houses with unusualiy high indoor radon concentrations, thereby permitting the targeting of ultigating measures for people subject to unacceptably high radon daughter exposures. One element in this strategy would be adoption of criteria for radon concentrations at which infiltration-reduction is recommended and criteria for implementation of mitigating measures. A second need, pertafning also to other excluston classes, is further development and testing of mitigating measures.

Altering the wood-stove exclusion is hampered by lack of detalled Information characterizing wood-stove emissions generically, conbined with the difficulty and expense of monitoring the variety of pollutants in homes th:- might be tightened. It is known that wood stoves can cause Indoor concentrations of carbon monoxide, nitrogen dioxide, and suspended particulates comparable to outdoor a1r quality standards. In addition, wood burning produces organic materlals that are of particular concern because of thelr potentlal carclnogeniclty. Because of the potential significance of these pollutants, one strategy is to perform a comprehensive array of measurements, a possibility that ts not atcractive, considering the substantial instrumentation and effort that would be required. An alternative possibility is to extend the research BPA is now supporting on wood-stove emissions to include nore complete characterization of pollutant entry paths and rates, as well as thefr dependence on Installation and operational factors. Such an irvestigation would provide a more substantial basis for identifying cases in which the wood-stove excluston could be lifted. This information would be useful whenever it is acquired, even if after complezion of an Environmental Impact Statement.

Conclustons

Of the two major exclusion classes, that for radon has the greatest potential for reformulation in the near future to permit offering of inflitration-reducing measures to a slgntflcantly larger number of homes than at present; a comparable basis for changing the wood-stove ex:lusion does not yet exist. It also appears feasible to offer infiltration-reducing measures, in some cases, even if an unvented combustion appliance or UF foam Insulation is present: for gas stoves, if provision of a ventilation hood is deemed adequate, ard for UF foam insulation, if monitoring demonstrates low formaldehyde levels.

In the interest of significantly expanding the offerfing of infiltration-reducing measures, whlle avolding significant adverse effects, serious consideration should therefore be given to modification of the exclusions related to radon, including proviston of monitoring and characterization efforts, as well as the offering of mitigation 
measures where approprlate. At the same $t I m e$, more complete characterizatiun of pellutants from wood-burning appliances can proceed as a basis for any declsion to alter related exclusions. Both of these efforts, as well as investigation of control technjques, will not only benefit the weatherfiation program durtng the period when the Environmental Assessment is applicable, but also provide a continuing basis for proceeding after completion of the Environmental Impact Staterent. 
PART I. IIIFILTRATIOSI REDUCTIOH, IIDOOR POLLUTIOH, AND COUTROL MEIASURES

The Bonneville Power Administration (BPA) is engaged in a weatherization program whose purpose is to make avallable measures for reducing electricity use in homes that use electrical heating. A number of the measures that are included in the program have the effect of reducing the ventilation rate in the structures in question, thereby not only saving energy but also Increasing the potential for increased concentratlons of indoor-generated alrborne pollutants.

In order to avold having a significant impact on the health of occupants, arfsing from Increases In Indoor pollutant concentration, the Environmental Assessment prepared by BPA In connection with the weatherization program provided that measures that substantially affect infiltration would not be of fered to certain classes of homes. These homes were excluded on the basis of house characteristics that may serve as indicators of higher-than-average sources of indoor pollusants. An addendum to this document has been prepared by BPA, summarizing the courje of events that led to withholding of Infiltration-reducing measures from spectific houstng classes.

The purpose of this document is to examine the list of excluded classes of homes and to delineate an approach for modifying that ilst in order to increase the number of houses for which infiltration-reducing measures are offered. Before proceeding to the methodology for altering the exclusion liat, it is useful to examine the background against which such changes way be made.

The first part of this report therefore reviews, in section 1 , the nature of the weatherization program, particularly with respect to infiltration reduction, then goes on in section 2 to survey what is known about the sources and concentrations of indoor pollutants, as well as their health effects. Finally, techniques for controling levels of Indoor pollutants, whether by source control or by ventilation and afr cleaning, are reviewed in section 3. This background provides a basis for Identifying the main considerations relevant to changes in the exclusion list and for formulating the elements that ought to be available in conjunction with such alterations. 
A. Heather1zation Measures.

The Bonneville Power Administration (BPA) has proposed a ten-year program to encourage fhe weatherization of electrically heated homes in the Pacific Iorthwest. The purpose of this program is to reduce residential energy demand by Increasing the efficlent use of energy in space heating. It 18 expected that 312,000 electrically heated residences (790,000 occupants) In the states of Washington, Oregon, Idaho, and western Montana w111 be weatherized.

The weatherization measures can be divided into two groups. The first group, to be offered to owners of all houses eliglble for weatherization consists of the following measures:
(1) celling and attic insulation
(2) floor Insulation
(3) Insulation of unfinished walls
(4) vapor barriers
(5) Insulation and sealing of a1r ducts
(6) water pipe insulation
(7) dehumidif 1 er
(8) clock thermostat

Except for measures (4) and (5), the above measures do not alter inf11tration rate, $1 . e .$, the rate at which inside air is replaced by outside a1r by movement through the building envelope. They therefore do not affect existing contaminant levels, in any direct way, by reduction of ventilation rates. In contrast, sealing of afr ducts that are located in non-space-conditioned areas, in accordance with measure 5, can reduce the amount of outside alr reaching living areas of a residence. And installation of a vapor barrier in the floor of a residence (measure 4) may also reduce infiltration. (In addition, measure (7) may affect the emission rate of formaldehyde from buflding materials and insulation containing urea-formalilohyde.)

If certain criterla (to be discussed ia Part II, on the exclusion methodology) are met, the following measures w11l also be offered:

(1) caulking

(2) weatherstripping

(3) storm windows and doors

(4) outlet and switchbox gaskets.

These measures may decrease the amount of a1r infiltrating Into the residence and thus may increase the concentrations of contaminants generated within the residence. The effects on infiltration rate of these four neasures and the consequent effect on Indoor afr quality will be discussed in the context of specific characteristics of the Pacific Northwest housing stock. (Furthermore, thermal panes would be offered only in homes meeting the exclusion criteria, the intention being to avold creating an incentive for adoption of this measure as an alternative to lesg expensive storm windows.) 


\section{B. Ilousing Characteristics}

During the last quarter of 1979 the Paçific Nlorthwest Residential Energy Survey was carried out for BPA. 2 This survey contains useful information on characteristics of residential bulldings throughout the BPA area. Table 1 1llustrates those characteristics that will affect the expected reduction in infiltration rate from weatherization measures and that may be related to speclfic sources of Indoor alr contaminants. We can see that only 1.07 of electrically heated residences use either natural or bottled gas for cooking, and only $1.5 \%$ use natural gas or kerosene for heating hot water. A secondary heating source is used by $42 \%$ of electrically heated houses. $37 \%$ of all electrically heated residences use wood as a secondary heating fuel and 0.57 use fuel ofl, gas or coal. Of those electrically heated residences using wood as a secondary heating fuel, $85 \%$ employ 11 replaces and $15 \%$ employ wood burning stoves. Turning to other fuels, only a very small number (less than $0.5 \%$ ) of electrically-heated resldences use non-portable roon heaters as secondary heating equipment. One third of these heaters, which use oll, kerosene or natural gas, have no flue or vent to take combustion products outdoors.

Other factorg that ifight affect Indoor air pollutant source strength ate shown in the second group of characteristics in Table 1 . The first three affect radon source strength while the next two affect formaldehyde source strength. The only significant Information avallaile concerns foundation type; $42 \%$ of electrically heated homes have full crawl spaces, $25 \%$ are bullt on cogcrete slabs, $12 \%$ have full basements and $10 \%$ have partial crawl spaces." Itsse houses with ventilated crawl spaces may have lower radon levels (all other factors baing equal) in their living spaces than houses without crawl spaces. The last group of characteristics concerny factors that affect inflitration rate. These are discussed next.

\section{Infiltration Rate Reduction fron Weatherization}

A key factor in determining the potentlal effect of the weatherization program on Indoor air quality is the ability to determine the reduction in infiltration rate achleved by weatherization. The measures listed below are the ones expected to reduce infiltration rates in residential bulldings:

(1) caulking

(2) weatherstripplng

(3) Installing storm windows and doors

(4) Installing outlet and swtchbox gasiets

\footnotetext{
*Based on Informally avallable information (rather than formal surveys), the proportion of houses with wood stoves is increasing rapidly. As many as half the electrically heated houses served by BPA nay now have such stoves.

** "ilssing responses have been eliulnated when frequenctes are calculated.
} 
Table 1. Salected Buflding Characteristics of Electrically* lleated Ilomes in BPA Area ${ }^{+}$

Combustion Sources

Primary Jeating Systems

Use of Secondary Heating Equipment

Secondary llearing Fuel

Secondary lleating Equipment

Cooking Fuel

llot water heater fuel

Factors Affecting Other Sources of Pollutants

Foundation Type

Vapor Barrier on Ground Under Hlouse

Domestic Hater Service

Wall Insulation - U.F. Foam

Particle Board, Plywood, etc.

Factors Affecting Infiltration Pate

Buflding iype

Air Conditioning Systems

Weatherstripping on Windows and Doors

Caulking Around Windows and Doors

$S$ torm Windows

Age of Buildings
$64 \%$ bullt in unft, $27 \%$ furnace with duct $4 \pi$ heat pump

45\% yes, 557 no

88\% wood, 10\% electric1ty, 17 nat. gas (1..C.)

737 wood fireplace, 137 wood burning stove,

77 portable heaters, 2.5 other electric

997 electricity, 1.0\% li.c.or bottled gas

98.5\% electricity, 1\% .I.C.., 0.5 kerosene

427 full crawl space, $10 \%$ partlal craw space

12\% full basement, $25 \%$ slab on grade

517 yes, $49 \%$ no

Ilo information avallable ${ }^{* *}$

tho Information avallable

llo Information avallable

12\% mobile homes, $58 \%$ single family,

1975 or more units, 117 other

$28 \pi$ yes, $72 \pi$ no

$38 \%$ on all, $20 \%$ on some, $36 \pi$ none

447 on all, $12 \%$ on some, 447 none

$52 \%$ on all, 67 on some, 427 none

847 pre $1978,16 \% 1978$ or $197 \%$

*Primaty teating fuel is electricity, mobile homes excluded.

** Survey did not discriminate by type of f111 (1.e., UF feam, etc).

*** Survey did not ask this question, however, a larg: percentage

of homes use ground water. See Environmental Assessment, Page A-4

+All staristics are derlved from the Paclfle Northwest Resident lal

Energy Survey by Elrich and Lavidge Inc. July 1980.

Frequencles have been ad justed to eliminate unreported and don't

know responses. 
(5) sealing of leaks in air ducts

(6) floor insulation vapor barriers.

Data fron the following weatherlzation studies have ieen analyzed:
(1) Iledford, Oregon
(2) Hsdway, Hashington
(3) Walnut Creek, Calı́ ì nia.

These were the only weatherization studies for which carefully documented data were avallable on "before" and "after" leakage areas or inflltration rates and for which the level of effort expended in the retrofft was specifically accounted for and within the range of efforts expected in the BPA program. In some cases, infiltration rates wera seasured dfrectly by a tracer gas decay method, but in most sases, only a1r leakage measurements were performed.

The concept of effect tve leakage area is central to a predictiye grodel of infiltration developed at Lawrence Berkeley Laboratory (I.BL). 3, 4 The procedure for determining the effective leakage area of the bullding envelope uses the technique of fan pressurization. In this technique, a fan is temporarily sealed into the shell of the house. The fan speed is afjusted to produce a specified pressure drop across the shell, and the flow rate through the $f$ an is measured. The ef fentive leakaga area is determined by fitting the measured data points of flow versus pressure to the equation $0=r(\Delta P)^{n}$, where $?$ is afr flow, $\Delta P$ is the applfed pressure drop, and $Y$, and $n$ are coefticients obtalned from a regression analysis. The flow is then extrapolatec $=0$ the pressure regime driving natural infiltration (4 Pascal is used), and he effective leakage area, $A_{e f f}$ is determined from the equation

$$
A_{\text {ef F }}=\varrho_{4} \sqrt{\frac{\rho}{2 \Delta P}}
$$

where $\rho$ :s the densfty of afr $\left(1.2 \mathrm{~kg} / \mathrm{m}^{3}\right), \Delta \mathrm{P}$ is 4 Pascal, and $\mathrm{O}_{-4}$ is the flow at 4 Pascal. Given the ef fect ive leakage area, local windspeed and temperature, bullding height, and varlous shlelding factors, the Infiltration rate can be calculated.

The results of the three weatherization studies are displayed in Table 2 which shows the reduction In inflltration race or leakage area (as appropriate) achfeved by the specifled weatherization measures. The first two houses in lledford, Oregon showed average infiltration rate reductions of 20 and $30 \%$, respectively, for measures $A, B$, and $C$ which do not involve use of a blower door and caulking. The infiltration rate In the first house was reduced fron an average (over two weeks) of 0.62 to 0.49 ach with the addition of storm doors and windows, the replacement of two sliding glass doors, and the weatherstripping of doors. The second house's infiltration rate was reduced from 0.82 to 0.58 ach with the addition of storm doors and windows and the replacement of one sliding glass door. The doors were already weatherstripped in this house. The other seven houses in ledford showed no statistically significant. reduction in leakage area (which is assumed to be proportional to infiltration rate) when measures $A$ and $C$ sert carrled out. The reason $g$ iven for this result is that the ductwork, which was located in unconditirned 
Table 2. Summary of Infiltration and Leakage Area Reductions

fron Weatherization.

\begin{tabular}{|c|c|c|c|c|}
\hline City & Houses & $\begin{array}{c}\text { Infiltration Rate } \\
\text { Reduction }\end{array}$ & $\begin{array}{c}\text { Average } \\
\text { Leakage Area } \\
\text { Reduction }\end{array}$ & $\begin{array}{c}\text { Weatherization } \\
\text { lfeasures }\end{array}$ \\
\hline Medford, Oregon & $\begin{array}{l}2 \\
7\end{array}$ & $20 z, 30 z$ & $\mathbf{0}$ & $\begin{array}{c}A+B+C \\
A+C\end{array}$ \\
\hline Nidway, Washington & $\begin{array}{l}6 \\
6 \\
6\end{array}$ & & $\begin{array}{l}147 \\
27 z \\
20 z\end{array}$ & $\begin{array}{c}A+D \\
F \\
E\end{array}$ \\
\hline Walnut Creek, California & 19 & & 257 & $\mathbf{E}$ \\
\hline
\end{tabular}

* Same six houses that already recelved $A+n$ weatherization measures.
$A=$ add storm doors and windows
$B=$ weatherstrip doors
$C=$ replace sliding glass doors
$\mathrm{D}=$ Caulk around foundation $\mathrm{s} 11 \mathrm{l}$
$E=$ one day "house doctor" progran which Includes use of blower door to find and plug leaks in building shell
$\mathrm{F}=$ same as $\mathrm{E}$ but two days taken 
spaces, was very leaky, so the potentlal for reduclng alr leakage was not fully realized.

In lidway, Washington, twelve relatively tight (with average infiltration rates all less thann 0.5 ach for the heating season) houses were weatherized in two phases. In Phase $I, 6$ houses had storm doors and windows added and caulking around the foundation s111. The average zeduction in leakage area was $14 \%$ with a range of $n$ to $43 \%$. In Phase II, the house doctor technique was used where, In addition to weatherstrlpping, a blower-door, smokesticks, and an infra-red scanner were used to detect air leaks, so that they could be plugged by caulking and taping. When the procedure was carried out in the first six houses, an additional 20\% reduction in leakage area was achleved for a total of a $31 \%$ reduction. In $\mathbf{3 1 x}$ other unweatherfzed houses a $31 \mathrm{mllar}$ house doctor approach was used to achieve a $27 \%$ reduction in infiltration rate. In this case, twice as much time ( 2 person-days) was spent weatherizing the houses.

The last weatherization study took place in Walnut Creek, California. A one-day house doctor approach was used to achieve an average $25 \%$ reduction in Ieakage area In 19 houses. The range of reduction was 8 to 61\%. As might be expected, the 617 reduction took place in a very leaky house.

Summarizing these results, it appears that tightening measures, including "house doctor" treatment, can be expected to reduce effective leakage area on the average about 20 to $30 \%$, with a range for individual houses of zero to $60 \%$ reduction. Since the leakage area approach does not include natural ventilation from door and window opening we should expect a somewhat smaller percentage reduction in tocal ventilation rate than $g i v e n$ by the leskage area reduction.

References for Section 1 and 2 are listed after Section 2. 


\section{IIDOOR AIR POLLUTAIT SOURCES, COHCEITRATIOHS, AHD HEALTI EFFECTS}

During the past several years a large amount of data has been accumulated on the levels of indoor alr contaminants in residential bulldIngs at varying infiltration rates. Less is known about the health effects arlsing from long-term exposure to such contaminants at the concentrations found in residential bulldings.

Table 3 lists the major outdoor and indoor sources of Indoor afr pollution and some of the important pollutants they emt. Outdoor generated pollutants will penetrate, to varying degrees, a bullding's envelope. Pollutants generated indoors will remain there for a period of time largely determined by the bullding's ventilation rate and the chemical reactivity of each pollutant. Medsurements have shown that a bullding's envelope acts as a screen to many outdoor pollutants, and lower concentrations of pollutants such as $\mathrm{SO}_{2}, \mathrm{HO}_{2}$, and ozone will be found Indcorg than outdoors (where Indoor sources of these pollutants are absent) ${ }^{8}$. The Indoor-generated pollutants that are of most concern In residential bulldings are radon, formaldehyde, and combustion products such as nitrogen dioxdde, carbon monoxide, carbon dioxide, and reapirable particles. A review of our present knowledge of indoor alr contaminants found in residential bulldings follows.

\section{A. Radon}

Sources and Concentrations

Radon, a radioactive inert gas, is a decay product of radium, which is found in small concentrations in rock and soll. The radon 1sotope of most concern, radon-222, has a half-life of 3.8 days; it decays into polontun-218, which also decays radloactlvely (these decay products of radon are known as radon daughters). Several members of the decay sequence (which ends in lead-206) are chemically active and may attach themselves to dust particles in the air.

There are three 1mportant ways in which radon may enter buildings: (1) by transport from soll through cracks and openings in the structure or around the foundation, (2) through emanation from earth-derived bullding materials such as concrete, and ( 3 ) by transport in water and natural gas. The concentration of radon In residences depends on several factors: the location of the building, the materials used to construct It, Its foundation type, pathways for alr transport from soll to basement, the source of 1 ts water supply, and the average ventllacion rate.

The soll under a house can be expected to be the principal fontributor to the Indoor radon concentration in many cases of corcern". Measured concentrations of radon vary over three orderg of magnitude $\left(90^{1-50}\right.$ $\mathrm{pCl} / 1)^{\lambda}$ In living spaces of homes throughout the United States, 10 and most of this variability appears to depend on how much radon enters from the soll. There is no reason to belleve that the range of

\footnotetext{
"pC1/1 equals $10^{-12}$ Curies per 11ter. $10^{-12}$ Curies is an amount of radioactive material that yields .037 decays per second.
} 
Table 3. Summary of Sources and Types of Indoor Afr Pollutants

Source

Major Pollutants

Outdoor

Stationary Sources

$\mathrm{SO}_{2}, \mathrm{CO}, \mathrm{HO}, \mathrm{HHO}_{2}, \mathrm{O}_{3}$, hydrocarbons, particles

Mobile Sources

So11

$\mathrm{CO}, \mathrm{HO}, \mathrm{HO}_{2}$, lead, particulates

Radon

Indoor

Building Construction Iaterials

Concrete, Stone

Radon

Particleboard, Plywood

Household Furnishings

Formaldehyde

Insulation

Formaldehyde, asbestos

Adhesives

Organics

Combustion Appliances

Using Gaseous Fuel

CO, Ho, formaldehyde, particles

Gas Stoves

Indoor Water Ileaters

Unvented Space lleaters

Gas Wall Ileaters

Combustion Appllances

Using Solid Fuels

Wood/Coal Burning Stoves

Fireplaces

Iluman Activities

Smok1ng

$\mathrm{CO}, \mathrm{HO}_{2}$, IICH, organics,

particulates, odorants

Aerosol Spray Dev1ces

Fluorocarbons, vinyl chloride, $\mathrm{CO}_{2}$, odorants

Cleaning and Cook1ng Products

$\mathrm{CO}, \mathrm{HO}_{\mathrm{X}}$, hydrocarbons,

aldehyles, polycyclic organic matter

llobbies and crafts

Organics, odorants

Organics, Odorants

Iluman Oscupents

Metabolic Activity

B1ological Activity

$\mathrm{H}_{2} \mathrm{O}, \mathrm{SO}_{2}$, odorants

M1croorganisms

At tached Carage

$\mathrm{CO}, \mathrm{HO}_{2}$, lead, particulates 
Although these are not the major concern in this document, there are special areas of the country where construction materials have been made out of uranium mill tallings or phosphate wining slag, both high in radium content. For example, phosphate slag has been used in the manufacture of insulation, and this insulation has been uged in residences in Washington. Additionally, phosphate slag was widely used from 1962-1977 as aggregate for the concrete foundation of homes bu1lt in southeastern Idaho. II

Other factors that have been found to be of Importance in influencIng the concentration of radon and 1 ts daughters in residences are whecher groundwater is used for the domestlc water supply (use of groundwater may lead to relatively higher concentrationg, if this water ins high radon concentrations) and whether the foundation type is a vented crawl space (may lead to lower concentrations) or other type such as an unvented basement or slab on grade. of course, the ventilation rate w11 also influence the concentration of radon in a residence. If the source strength ts held constant, a halving of the ventilation rate w11 approximately double the radon concentration (assuming, as is usually the case, that the indoor radon concentration is much higher than the outdoor concentration).

Itealth Fiffects

The main health hazard from radon and its daughters is an increased risk of lung cancer resuleing from an added radiacion dose to the lung tissue. As the first four radon daughters have short half-11ves ( 30 minutes or less), if they are tnhaled and deposited in the lungs, they can expose the surrounding tissue to alpha rays before being removed by the body's lung-clearance mechanisms. The health risk from radon daughters in residential bulldings depends upon the time integrated exposure to radon daughters. For this reason, radon daughter concentratlons are ordinarily expressed in terms of the total alpha energy emitted as a result of the decay of these daughters, a quantity that conveys some sense of the potential alpha exposure to the lungs. This "potential alpha energy concentration" is expressed in units of work:ng level (WL)*. Radon daughter concentrations vary from 0.001 to 0.3 WL in U.S. homes. Since the risk of cancer from radiation is related to cumulative exposure, the effect of 1 ncreased radon daughter concentrations must be evaluated in terms of the duration of the exposure.

Integrated exposure or, equivalently, dose may then be expressed in terms of the working level month (WLII), where exposure ro 1 HL for 173 hours ylelds I whl. These units were origlnally based on the exposure of uranium miners to radon and Its daughters; hence the 173 working hours in one month. $\mathrm{m}$ a annual exposure assoclated with a constant radon concentration

\footnotetext{
* One wh has a value of $1.3 \times 10^{5} \mathrm{MeV} / 1$, the potential alpha energy per unft of volume that would be associated with air containing approximately $100 \mathrm{pCl} / 1$ of each of the short lived daugheers.
} 
of $1 \mathrm{pCl} / 1$ is approximately $0.25 \mathrm{KLI}^{* *}$. The WLll is dose for several reasons. For example, the degree to which daughters are deposited in the lungs depende on particle size and breathing rates differ between workers and the general population (they are less for the general population). Considering breathing rates alone, if uraniun workers are taken to be the standard for evaluating health risks, then the public would have to be exposed to twice the number of hours as in a normal working month ( 173 hours) to accumulate the same exposure as a uranium miner (assuming the same fl exposure). Another complicating factor is that when the health risks to children are considered, we must take Intc account the facts that children have a higher respiratory rate than adulte but a smaller vital capecity.

Huch of our knowledge about the human health effects of radon and Its daughters $1 \mathrm{~s}$ based on the experience of underground urantum miners. These winers were exposed to radiation at dose rates much higher ( 100 times) than would ordinarily be experlenced by occupants of residential bulldings, and they developed lung cancer at a higher rate than the general population. Whereas an occupant of a residential bullding may in rare cases be exposed to radon daughter concentrations as high as 0.1 WL, uranium miners were, unt1l recently, exposed to 1-20 WL. The cumulative exposures ( $\mathrm{n}$ WLlt) at which additional human and antmal cancers have been demonstrated are generally higher by an order of magnitude or mrre than those chararteristic of the general indoor environment. Thus, In order to predict the health effects of decreased Indoor ventilation and a corresponding increase in exposure to radon daughters, it is usually necessary to extrapolate below the range of exposures for which effects are known. The generally accepted method of predicting cancer Induction rates at low dose rates is to assume a inear no-threshold dose-response function. Using the linear hypothesis, and data from studies of urantum miners in the U.S. and Czechoslovakia, the number of lung cancers per unft of exposure to radon daughters ranges from 2.2 to $8 \times 10^{-6} /$ year/whll. 12 Assuming that the upper limit of this range holds, If a militon people are all exposed to 1 whll, then 8 people per year would be expected to contract lung cancer from this exposurc. We are assuming here that the actual radiation dose from 1 WLI of exposure 1 s the same for the general population and uranium miners. Our predictions of excess lung cancers due to Increased radon daughter concentrations w111 have more than a factor of four uncertainty due merely to the uncertainties in estimating $b$ th actual doses and risk rates in miners. Applying this information to the general population Increases the uncertainty even moro $(e . g .$, ref. 12a).

Table A-1 in Appendix A 118ts some proposed and existing standards for radiation exposures fron radon and its daughters. With the exception of the Swedish guideline, present Indoor standards or guldelines are generally designed to deal with specific problems rather than to set overal 1. standards.

"This result is ubtained assuming a value of 0.5 for the equilibrium factor, which is defined to be the ratlo of actual daughter potential alpha energy concentration (PAEC) to the PAEC were each daughter to have the same activity concentration as that of the radon actually present. Ventilation and plateout of daughters to walls and other surfaces reduce the ratio of daughters to their parents below one. 


\section{B. Forma1dehyde}

Sources and Concentrations

Formaldehyde (HCIIO) is primarily an Infoor-generated pollutant; its sources are bullding materials, furniture, carpets, combustion appliances, tobacco smoke, and consumer products. Formaldehyde is used in a wide varlety of products, mainly in urea, phenolic, melamine, and acetal resins. These resins are present in 1nsulation materials, particleboard, plywood, textlles, adhesives, etc., that are used in large quantitles by the bullding and furniture trades. Emission rates for formaldehyda emitted in the indoor environnent are generally unknown.

Urea-formaldehyde (UF) foam has been used extensively as thermal insulation in the walls of existing residential bulidings. It is Infected into wall cavities through holes that are subsequently sealed up. Installation involves mixing partially polywerized UF resin with a foaming agent and an acld catalyst under pressure that forces alr 1nto the mixture to create a foam. Under certain clrcumstances, large quant1tles of formaldehyde may be released into the building. Even proper formulation and mixing of UF-foam w111 not entirely prevent some formaldehyde release. The U.S. Consumer Products Safety Conmission has recencly banned the use of urea-formaldehyde foam Insulation.

The superior bonding properties and low cost of formaldehyde polymers make them desirable chemtcals for use in resins for the production of bullding materials such as plywood and particleboard. Dreaformaldehyde resin is the most common adhesive used in Indoor plywood and patticlebcard. Plywood is composed of several thin sheets of wood glued together with UF resin. Particleboard is made by saturating small wood shavings with UF resin and pressing the resulting mixture into the final form. Particleboard can emit formaldehyde continuously for a perlod of years. In bulldings in which these wood products are used for partition walls or furniture, formaldehyde may reach concentrations sufficient to cause eye and upper respiratory 1 rritation.

Formaldehyde is also produced during combustion processes such as in gas cooking and heating. Chamber studies have Indicated that combustion processes can contrfbute significant quantities of formaldehyde to the Indoor environment ${ }^{3}$.

A substantial number of residential bulldings In the United States and other countries have been monitored for formaldehyde and total aldehyde concentrations. Particularly high concentrations (2.4 ppm) have been found fn moblle homes where occupants have compla1ned about


efficlent house in llatyland has been fogupd to have Indoor formaldehyde concentrations that exceed $120 \mathrm{\mu g} / \mathrm{m}^{3} \times \mathrm{S}^{2}$. Measurements at another

$\star_{1} \mathrm{ppm}=1200 \mathrm{\mu g} / \mathrm{m}^{3}$.

** $120 \mathrm{\mu g} / \mathrm{m}^{3}$ is the promulgated standard in the letherlands ant has been proposed in other nations. See table $\mathrm{A}-2$. 
energy-efficlent house ( 0.4 ach average) in California Indicaced that the presence of furntture plays a gajor role in influencing the ambient levels of formaldehyde indoorg. 16 The average ficto concentration Increajed from 80 to $223 \mu \mathrm{g} / \mathrm{m}^{3}$ when furniture was adjed to the vacant house. A further Increase was noted when the house was occupled, very likely because of such activities as cooking with gas. Formaldehyde levels were also measured in four energy-efficlept houses ( 0.2 ach average at time of measurements) in Eugene, Oregon 17 . Outdoor levels were less than $3 \mathrm{ppb}$ and the average 1 indoor levels were 50,55, 94, and 100 ppb for the four houses.

Twelve houses in Midway, Washington wefe wonitcred for formaldehyde levels before and after weatherization 18 . In general, because these houses were more than thirty years old (aged building materials) and had no combustion appliances, formaldehyde levels were low. Flowever, in one home with new furniture the average level was found to be $79 \mathrm{ppb}$. Wher the furniture was moved to another house the formaldehyde level jumped from <5 ppb to $79 \mathrm{ppb}$, while dropping in the original house to $13 \mathrm{ppb}$. The outdoor IICHO concentrations were all below the detection $11 \mathrm{mit}$ of 5 ppb.

The emission rate of formaldehyde from building materials, insuldtion and furniture is known to decrease with time. The half-ilfe of formaldehyde contalned in particleboard is not known but informal est1mates range from 1-4 years. It is also known that humidicy levels affect formaldehyde emission rates. Higher humidity levels increase the HClO enission rate. Decreasing infiltration rates in residential buildings may cause higher humidity levels and thus higher HCHO concentrations. This proces 8 will be discussed further in the section on measures for pollutant control.

\section{Ilealth Effects}

Formaldehyde is a colorless, very water soluble gas with a pungent odor that can be detected at levels well below 1 ppl by wost people. Connecting specific health effects to specific concentrations of formeldehyde is difficult because people vary widely in their subjective responses and complaints. Interpretation of the health effects of formaldehyde must also consider the expostre time of subjects; short-term tnhalation studies cannot accurately predict the effects of long term continuous formaldehyde exposures of bullding occupants. Ddor ifritation may be followed by tole rance after several hours of exposure and modify rits response to formaldehyde.

Reactions to formaldehyde may be brought about by contact with skin and the mucous merbranes of the eyes, nose and throat. Exposure to formaldehyde may cause burning of the eyes and irritation of the upper resplratory passages at concentrations of $0.05-0.5 \mathrm{ppm}$, depending on individual gansitivity and environmental conditions (temperature, humidity, etc.). Table 4 summarizes the reported health eftects of formaldehyde at varlous concentrations, based on a llatlonal Research Council Committee on Aldehydes report . High concentrations ( $f f_{\text {ew }} p$ pu) often produce coughing, constriction in the chest, and wheezing. Studies in rats and mice have shown that concentrations of formaldehyde of a few 
Table 4. Peported Ilealth Effects of Formaldehyde at Various Concentrations ${ }^{a}$

Effects $\begin{gathered}\text { Formaldehyde } \\ \text { Concentration, } \\ \text { ppm }\end{gathered}$

llone reported

Neurophysiologic effects

0-0.05

Odor threshold

Eye irritation

Upper alrway iritation

Lower alrway and pulmonary

$0.05-1.5$

$0.05-1.0$

$0.01-2.0^{b}$

$0.10-25$

5-30

effects

Pulmonary edema, Inflammation,

pneumonta

Death

50-100

$100+$

aperived from National Research Council (Ref. 19).

bithe low concentratior. $(0.01 \mathrm{ppm})$ was observed in the presence of other pollutants that may have been acting synergisticalis. 
ppm for several months Induce nasopharyngal carcinoma 20 .

Table A-2 in Appendix A summarizes varlous recommended and promulgated indoor formaldehyde atr quallty standards. There is no outdoor standard for formaldehyde in the United states, but the American Industrlail Hygiene Association recommends a guideline of $0.1 \mathrm{ppm}$. The lletherlands, In 1978 , established an indoor standard of $0.1 \mathrm{ppm}\left(120 \mu \mathrm{g} / \mathrm{m}^{3}\right)$ maximum permissible concentration. Denmark, Sweden, and West Cermany are $=? .1$ considering establishing a standard at approximately the same value $(0.1 \mathrm{ppa})$.

\section{Combustion Products}

\section{Sources and Concentrations}

A wide range of combustion products can be emitted by indoor sources such as combustion appliances and cigarette smoke. These include carbon monoxide $(\mathrm{IO})$, carbon dioxide $\left(\mathrm{CO}_{2}\right)$, water vapor $\left(\mathrm{Il}_{2} \mathrm{O}\right)$, nttric oxide (IO), nitrogen dioxide $\left(\mathrm{HO}_{2}\right)$, sulfur dioxide $\left(\mathrm{SO}_{2}\right)$, formaldehyde (HCtO), and respirable particles. Combustion appliances that may be found in residential bulldings are gas-fired stoves, Indoor gas-fired wacer heaters, unvented gas-fired space heaters, gas-fired and oll-fired furnaces, and portable kerosene-fired space heaters. Wood-burning stoves and fireplaces and coal- or wood-burning furnaces may also contribute pollutants such as hydrocarbons and polycyclic organic mater (PUH) to the Indoor environment in addition to the aforementioned pollutants. Automobile exhaust from vehicles in attached garages can also be a source of combustion byproducts in buildings.

\section{a. Gas Stoves}

There have been many fleld studtes that monftored the concentration of varlous pollutants in residential bulldings with gas stoves. In almost all cases, Indoor/outdoor ratios of $\mathrm{CO}, \mathrm{HO}_{2}$, and $\mathrm{IO}$ have been greater than one. In a number of cases, levels comparable to existing health standards (see Table A-3, AppendIX A), of $\mathrm{IO}_{2}$ and $\mathrm{CO}$ have been reported. For example, $\mathrm{HO}_{2}$ and $\mathrm{CO}$ concentrations in a kitchen of a suburban house in Connecticut avefaged approximately 0.05 and $3.5 \mathrm{ppm}$ respectfvely, durfing the winter. 21 serles of fndoor alr quality measurements were performed at an unoccupled energy-efficient research house In Calffornfa.2 $\mathrm{CO}$ and $\mathrm{HO}_{2}$ were measured in several rooms durfng a period when the infiltration rate varied between 0.33 and 0.44 ach. With a "typical" gas stove operation scenario taken from an American Gas Assoclation study, peak one-hour average $\mathrm{HO}_{2}$ levels in the kItchen and living room were 450 and $400 \mathrm{ppb}$, respectively, which exceeds the Callfornia short term standard of $250 \mathrm{ppb}(470 \mu \mathrm{g} / \mathrm{m})$. The outside level of $\mathrm{HO}_{2}$ was $70 \mathrm{ppb}$. The one hour $\mathrm{CO}$ outdoor standard of $35 \mathrm{ppm}$ was not exceeded anywhere in the house, although the indoor co concentration (a peak of $25 \mathrm{ppm}$ in the kitchen) was much higher than outdoors.

Controlled chamber studies have been perfomed to characterize the emlssions from a gas stove. Studies at LBL have shown that using the oven at $3500^{\circ} \mathrm{F}$ in a $27 \mathrm{~m}^{3}$ chamber with a ventilation rate of 1.0 ach, $\mathrm{HO}_{2}$ and HCto concentrations exceed the one-hour Calffornla $\mathrm{IO}_{2}$ standard 
and the Furopean nclio standard, respectively. ${ }^{23}$ To keep $\mathrm{HO}_{2}$ and nctio concentrations within the established alr quality limfts, either logal ventilation or an overall kitchen ventilation rate of at least $170 \mathrm{~m} / \mathrm{h}$ ( 5 ach) was required. Carbon monoxide and particulate concentretions at 1 ach are higher than outdoors iut lower than the relevant EPA standards. Emission rates of a large number of combustion products 55 om gas ovens and top burners can be found in a report by Traynor et al.

\section{b. Unvented Space Ileaters}

Several studies have been performed to assess the level of alr con. tamination from unvegnted gas-fired and kerosene-fired space heaters. Experiments in a $27-\mathrm{m}^{3}$ chamber with a portable, convective-type kerosene space heater show that at a ventilation rate of $1.9 \mathrm{ach}, \mathrm{CO}$ and particylate concentrations are $\mathrm{LOw}_{\text {, but, }} \mathrm{CO}_{2}$ and $\mathrm{HO}_{x}$ concentrations are high. 25 $\mathrm{CO}_{2}$ concentrations reach $5000 \mathrm{ppm}$, the occupational standard established by the U.S. Occupational Safety and llealth Administration (OSFA), after 45 minutes of operation. After 45 mimutes of operation, the $\mathrm{HO}_{2}$ concentration was greater than 1 ppm over background, four times the Calffornia peak one-hour outdoor standard.

Additional experiments with portable, convective and radiant kerosene heaters, in a $27 \mathrm{~m}^{3}$ chamber, found that $\mathrm{CO}_{2}$ levels can reach $10,000 \mathrm{ppm}$. $\mathrm{HO}_{2}$ levels exceeded the Callfornta one-hour standard of $0.25 \mathrm{ppm}-\infty$ by a factor of seven for the convective heater and by a faccor of 2 for the radiant model. 26 The heaters were operated for one hour at a fuel consumption rate of approximately $8,000 \mathrm{Btuh}$, and the alr exchange rate was 0.40 ach.

Emisglons from unvented gas-fired space heaters are highly dependent on the size of the heater, the manufacturer, and the state of cuning of the appliance. Eight heaters, rangling in size from 12,000 to 40,000 Btult were tested in a $27 \mathrm{~m}^{3}$ chamber. $7^{1} \mathrm{HO}_{x}$ and HCHO emission rates were found to be lower than for gas-fired stoves. CO and HCHO emission rates were found to be much more varlable than those of other pollutants and very sensitive to the state of tuning for some heaters. After 30 minutes of operation, typical pollutant concentrations were $4,000 \mathrm{ppu}$ of $\mathrm{CO}_{2}, 4$ ppm of $\mathrm{CO}, 1 \mathrm{ppm}$ of $\mathrm{HO}_{2}$, and $3 \mathrm{ppm}$ of $\mathrm{HO}$.

c. Wood-burning Stoves, Wood-burning Furnaces, and Fireplaces

Several studles have shown that wood buralng combustion sources are signiflcant sources of $\mathrm{CO}$, $\mathrm{NO}$, hydrocarbons, and respirable particulates Including polycyclic organic matter (PON).

Measurements show that pollutant emission rates from wood combustion can vary over a wide range. Co emfssions can vary from 4 to 400 grams per kilogram $(\mathrm{g} / \mathrm{kg})$ of wood burned; particulate emlssions can vary from 0.5 to $63.5 \mathrm{~g} / \mathrm{kg}$; total hydrocarbons from $0.2,50: a .5 \mathrm{~g} / \mathrm{kg}$; 110 from 0.2 to $7.3 \mathrm{~g} / \mathrm{kg}$; and POM from 0.004 to $0.37 \mathrm{~g} / \mathrm{kg} .28$ All of these pollutants can enter the living space under certain circusstances. 
Measurements in three suburban residences in the Boston area Indicated that woodburning produced elevated levels of total suspended particulates (TSP), respirable suspended particulates (RSP), jefined in this sfudy as particulates less than $3.5 \mu \mathrm{m}$ In size, and benzo-a-pyrene (BaP). 29 An all electric house (designated $A$ ) with a closed combustion woodburning sicove in the basement and an average ventilation rate of 0.68 ach was monitored over a two week. perlod. TSP in the 11ving spaces of Residence $A$ averaged 1.8 times the outdoors level on woodburning days and exceeded the secondary $24 \mathrm{hr}$ TSP outdoor standard of $150 \mu \mathrm{g} / \mathrm{m}^{3}$. RSP in residence $A$ averaged 1.4 times the outdoor level on woodburning days. Two other residences (designated $B$ and $C$ ) that had woodburning fireplaces exhlbited much higher indoor/outdoor ratios for TSP and RSP durIng woodburning days. BaP concentrations were measured only in houses $A$ and $B$ and were found to be flve and ten times the outdoor levels, respectively. Carbon monoxide was measured in residence $A$ and found to be at a higher concentration than outside when the wood stove was used, reaching a maximum of $5.5 \mathrm{ppm}$ on one day. It is important to note that, In residence $A$, higher contaminant levels than reported would have been found if sampling had occurred in the room where the woodstove was located.

Another study of three houses with woodburning stoves and furnaces showed elevated levels of $\mathrm{CO}, \mathrm{HO}_{\mathrm{X}}$, and $\mathrm{SO}_{2}$ during the period when these appliances were operated, although the pollutant levels observeg were generally below occupational and outdoor alr quality standards. 30 Particulates were not measured in this study. The average infiltration rates in these three houses -- called llouse A, llouse B, and llouse C -durling the measurements were $0.30,0.08$, and 0.40 ach, respectively. Both studies showed that the magnitude and mix of pollutants from woodburning stoves and furnaces can vary widely. Comparisons of 1ndoor pollution levels from wood-burning furnaces 1 n Houses $A$ and $C$ show that the magnitude of pollutant emissions from the appliances vary, for reasons not yet identifled. The major component of gaseous emissions also varles; for example, the dominant pollutant from the wood-burning scove in llouse $B$ was IJ; from the wood-burning furnace in llouse $A, C O$; and from the wood-burning furnace in llouse $\mathrm{C}, \mathrm{HO}_{2}$ : As mentloned earlier, loschandreas et al. observed a peak 1 -hour $C 0$ concentration of 5.5 ppm during stoking of a wood-burning stove, significantly higher than co levels measured In llouses A and B In Traynor's study, but lower than the Co levels from one of the wood furnaces measured. At this time the data on wood-burning appliances is limlted in scope.

\section{d. Tobacco Smoke}

One of every three persons between the ages of 17 and 64 smokes clgarettes regularly. Tobacco smoke is quite prevalent in residential homes; surveys in elghf, c1 $1 f^{1 e s}$ show that from 54 to $76 \%$ of homes have one or more smokers. 1,32 In addition, people are exposed to stioke at their workplaces and at other activities. Exposure of individuals to tobacco smoke of other people is known as passtve smoking.

A distinction can be made between mainstream and sidestream smoke enanating from cigarettes. lainstream smoke is undiluted and is pulled through the tobacco 1 nto a smoker's lungs. Sidestream smoke comes 
directly from the burning tobacco. Depending on smoking behavior, burning temperature, and type of filter, the conposition of mainstream smoke exhaled by a smoker varles substantially. Sidestream smoke is more 1mportant to the Involuntary swoker. Because of the length of the burn and the buzn temperature, sldestream smoke is a more Important source of local air contamination for many substances such as $C 0$, nicotine, ammonia, and aldehydes, than mainstream smoke. The passive smoker, however, does not recelve nearly as large a dose of smoke as the smoker.

A number of 1ndoor air pollutants arise from tobacco smoke; some of the more Important ones are particulates, CO, BaP, acrolein, nicotine, nitrosamines, and aldehydes. Residential measurements of RSP (defined as less :ian $2.5 \mathrm{\mu m}$ in size in this study) in elghty homes across six cities with and without smokers were made by Spengler et al. 33 Daily Indoor RSP concentrationg frequently exceeded $200 \mu g / m$ in komes with clgarette smokers. ${ }^{*}$ RSP levels were essentially the same $(\sim 23 \mu g / m)$ Indoors and outdoors in the homes without smokers. The mean RSP concentrations indoors for homes with one and two smokers were 43 and $75 \mu \mathrm{g} / \mathrm{m}^{3}$ respectively. These data, collected over a three year perlod, 1llustrate the contribution of cigarette smoking to indoor particulate concentrations.

Repace and Lowrey have conducted measurements of RSP in many bulldIng types with and without smokers present. ${ }^{34}$ The average RSP concentration in three residences ( $w 1$ thout fan $\mathrm{mixing}$ ) was $24 \mathrm{\mu g} / \mathrm{m}^{3}$. One measurement was performed during a cocktall party in a house with 2 of 14 occupants smokfing. The indoor RSP was $350 \mu \mathrm{gm}^{3}$. RSP concentrations measured in other bulldings (restaurants, meeting halls, sports arenas, etc.) with smokers present ranged from 55 to $700 \mu \mathrm{g} / \mathrm{m}^{3}$.

Pagsive smoking was shown to be, an 1mportant means of exposure to RSP In a study by Spengler et al. 35 Portable monitors were carried by several people for twelve hour periods on 15 sampling days. The mean RSP concentration in samples where participants reported passive c1garette smoke exposure was $40 \mu \mathrm{g} / \mathrm{m}^{3}$ compared to $22 \mathrm{\mu l}_{\mathrm{g}} / \mathrm{m}^{3}$ for the nonsmoking nonexpgsed particlpants. The outdoor concentrations averaged less than $15 \mu \mathrm{g} / \mathrm{m}^{3}$.

Carbon monoxide levels are known to be higher in bulldings with smokers. Most measurements have been performed in public bulldings; for example Sebben et al. have found co concentrations greater than $9 \mathrm{ppm}$ (the 8 hour outdoor standard) in restaurants and night clubs. 66 In most cases, the co concentration remalned below $35 \mathrm{ppm}$ (the one hour outdoor

\footnotetext{
*The short term (24h) outdoor standard for total suspended particulates (TSP) Is $260 \mu g / m$ (see Table A-3, Append $\overline{I x}$ A). However, this standard 1s Inapproprtate for particulates eutted from c1garetces, as the range of compounds is quite different than those found in outdoor atr.
} 
standard).

Ilealth Effects of Conbustion Broducts

a. U1trogen nioxides

Indoor combustion can have an Iuportant effect on the Indoor concentrations of nitric oxide (HO) ard nitrogen dioxide $\left(\mathrm{HO}_{2}\right)$. NItric oxide binds to hemoglobin to produce methemoglobin. llany of the adverse effects attributed to $\mathrm{CO}$ alone may be due to the combined action of collb and methemoglobin. Ho at 3 ppm is physlologically comparable with $C 0$ at 10-15 ppm. At concentrations of 0.05 ppn or greater $110_{2}$ may affect sensory perception, and produce eye irritation, especially with hydrocarbons present. Ht:zogen dioxide can produce transient and long-term danage to both small bronchial alrways and alveolar tissue. Ten minute exposures to $\mathrm{HO}_{2}$ concentrations of 0.7 to $2.0 \mathrm{ppm}$ produce increased a1rway rea lstance In humans.

The evidence of health effects from long term exposure to low concentrations of $\mathrm{HO}_{2}$ and $\mathrm{HO}$ is inconsistent. It is difficult to separate the effects of $\mathrm{HO}_{2}$ and $\mathrm{NO}$ from those of other alr pollutants and to obtaln populations that are equivalent in all respects except for lio, and 110 exposure levels. Two studies, one of the relationship between respiratory 11iness in primary school children in England and the use of gas for cooking and the other, of the relationship between lung function and respiratory 11 iness in children and the concentration of $\mathrm{HO}_{2}$ in their howes, suggese that there is a relationshjp fotween gas cooking, $\mathrm{HO}_{2}$ concentration, and respiratory 1llness. 38 lowever, a similar study by Keller et al. falled to establish any increase in resplratory disease or decrfose in pulmonary functions associated with the use of gas for cooking. ${ }^{39}$ Another study, which is still ongoing, Indicates that children In homes with gas stoves had a greater history of respira tory 11 Iness before age 2 than children in homes with electric scover. 40

b. Carbon Monoxide

At present, the most dangerous result of exposure to co occurs when combustion takes place without an adequate supply of a1r $(\mathrm{e} . \mathrm{g} .$, in closed garages). In such a situation co levels can reach $150 \mathrm{n}$ ppm, a life threatenting concentration. Carbon monoxide enters the body through the respiratory system and reacts primarily with the hemoglobin of the circulating blood. The affintty of hemoglobin for co is ove: 200 rimes that of oxygen. The absorption of $C 0$ is associated with a reduction in th: oxygen-carrying capactty of blood and also wth a reductio-. of the ease with which the blood gives up irs avallable orygen to the tissues. Experimental exposure of nonsmokers to 50 ppm for 90 minufes has been associated with Impairment in time-interval discrimiation. "This exposure is likely to produce a carboxyhemoglobin (Collb) level in the blood of about 2.5\%. This same cortb level wil occur with continuous exposure to I0-15 ppm co for 8 or more hours.

Tne current EFA outdoor CC standards ( $8 \mathrm{hr}-9 \mathrm{ppm}, 1 \mathrm{hr}-35 \mathrm{ppm}$ ) are mainly justified on the basis of adverse Co effects is patients with cardlac and perlpheral vascular disease and effectg of co on oxygenation 
of skeletal muscles in exercising nomal hum subjects. There appears to be an adequate safety factor between the lowest collb concentration that has been demonstrated to cause adverse effects and the waxiasl collb conceptration that can occur at 9 ppm Co for 8 hours or 35 ppis for 1 hour.

\section{c. Carbon Dioxide}

The present Feteral standard for carbon dloxide in the workplace is $5000 \mathrm{ppm}$ of alr by volume for a time relghted 8 hour dally average. liuch of the research on phystological effects of $\mathrm{CO}_{2}$ exposure has been done to establish safe limits for subarine crews and astronauts. The IIASA lint for a 6 month exposure in spacecraft is 10,000 ppa. The Bloastronautics Data Book states "that for prolonged exposures of 40 days, concentrations of $\mathrm{CO}_{2} \mathrm{In}_{4} \mathrm{~g}^{1 \mathrm{r}} \mathrm{Less}$ than 5000 ppa cause no known blochemical or other effect. ${ }^{42}$ Concentrations between 5,000 and 30,000 ppm cause adaptive blochemical changes which may be cor:sidered a mild physlological strain; and concentrations above 30,000 ppm cause pathological changes in basic physlological functions." Schafer in his review of submarine reeearch states "at a 15,000 ppm exposure, performance and physlologic functioning were not adversely affected, although acid-base and electralyte adaptation occurred as as result of continuous exposure. At levels above $30,000 \mathrm{ppm} \mathrm{CO}_{2}$, deterioration in performance nay be expected, as may alterations in basic phystologic functions, such as blood pressure, pulse rate, and metabolisn." 43 Sone Rusgfan studies find respiratory effects at $\mathrm{CO}_{2}$ levels as low as $1,000 \mathrm{ppm} .44$ The anpl1tude of the respir:tory wovement was reduced and peripheral blood flow Increased at this low concentration in laboratory experiments. It should be noted that occupational standards are weant to protect the adult healthy worker and may not be adequate to protect children, older people, and sick people. Thus, it is uncertain if occupational standards may be safely applied to the diverse population in residential bulldings.

\section{d. Particulates}

Since the respiratory system transports gases from the atmosphere to the lungs, a wide variety of particulate matter may be inhaled. Some of the inhaled particulate matter is deposited and retained in the various parts of the respiratory system. Two important factors determining the likelihood of particle deposition are particle size and density. Large particles $\left(>5 \times 10^{-6} \mathrm{~m}\right)$ have a small probability of reaching the alveoli, the air sacs in the lungs. Particulate matter may exert a torlc effect because:

(1) The particle may be intrinsically toxic due to its Inherent chemical or physical characteristics (e.g., lead and asbestos).

(2) The particle may act as a carrier of an adsorbed toxtc oubstance (e.g.., radon daughters can be adsorbed by particulates enitted in cigarette smoke).

(3) The particle may interfere with one of the clearance mechanisms in the respiratory system. 
Carbon particles, such as are emftted in combustion processes, are efficlent adsorbers of many organic and Inorgantc compounds and can carry toxtc gases such as $\mathrm{SO}_{2}$ fnto the lungs. This can lesd to a "potentlating" effect In the human body in which particles that contain an adsorbed toxt s substance Increase a person's physlological response to that toxic substance to a level above what it would be if the substance were present without the adsorbent particle.

Epidemiological studies indicate that particulates are associated with health effects of varying severity. Respiratory 1liness, especlally from chronic diseases euch as bronchitis and emphysema show the strongest positive assocfation with levels of particulate matter. ${ }^{4}$ Adverse health ffects have been observed for annual mean levels of as low as $80 \mu \mathrm{g} / \mathrm{m}^{3}$. Ilowever, these particulate leveis are usually associated with high levels of $\mathrm{SO}_{2}$ and the effects of the two have not been separated.

\section{e. Other Combustion Products}

As mentioned earlier, other combustion products may have adverse health effects on occupants of residential bulldings. Some of these pollutants are: hydrocarbons, nitric oxlde, benso-a-pyrene, and nicotine; the latter two resulting from clgarette smoke. Benzo-a-pyrene is known to be carcinogenic. ${ }^{46}$ Cigarette gmoke can cause ege, nose, throat, and respiratory irritation to passive smokers. There may also be an association between long term passive exposure to cigarette smoke

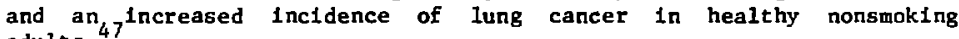
adults. 47

\section{Other Pollutants}

\section{Sources}

There are many other sources of Indoor alr pollutants that have not been specifically mentloned. These include the following: insulating materlals contalning asbestos; household products such as paints, aerosols, and cleanling flulds; cooking products such as greases, water vapor and odorants; bathroom activities that release water vapor and odorants; and humans and animals, which are sources of bacterla, viruses, fungl, odorants, and water vapor.

Ilealth Effects

Asbestos fibers can be released from pipes insulated with asbestos plaster and, if inhaled, may remain embedded in lung tissue for very long time periods. Asbestos $f$ ber Inhalation has been assoclated with lung cancer, asbestgis, and mesochelfoma (cancer of the membranes surrounding the Iungs). ${ }^{48}$ The assessment of the human exposure and adyerse health consequences due to the storage and use of consumer products is made difficult by the irregular, sporadic, and highly variable exposures, by scarcity of measurements, and by limited knowledge about the composition of many of the products. Knowledge about the synergistic effects of many air pollutants acting together on bullding occupants is also lacking. 
Microorganisms can produce infection, disease, or allergic reactions. Regpiracory virused and bacterla can be transitted frow person to person in bulldings and confined spaces. Some fraction of the Incidence of respiratory disease resulta from alrborne transidssion, but 1t is not clear what effect ventilation, air conditioning, or alr cleanIng will have on disease 1nc1dence. Several measurements have been made In public bulldings to determine the effect of reduced ventilation on the numbers of colony forming particles (CFP) per unit volune of atr. The Haval Bloscience Laboratory found that the number of CFP/m $\mathrm{d}$ (d) Increase with reduced ventilation but remined within the range of measurements taken $\mathrm{g}^{\mathrm{n}}$ a large group of bufldings where ventilation changes were not made.

Decreases in ventilection tend to increase the indoor relative humdity during the heating season. Excess water vapor 18 adsorbed or condensed onto drier or colder surfaces, causing deterioration or corrosion of bullding materials, furnishings, ete. Increased relative humidity may also promote the growth of molds, al jae, and fung1, which can cause an Increase in allergic reactions of bullding occupants. On the other hand, In colder climates my homes use humidifiers to increase molsture content of the a: $r$, in which cases reducing ventilation, thereby raising the humd dity, is an advantage. 
1. Revised Envfronmental Assessment, Proposed BPA Reglonwide Weatherization Program, Division of Energy Conservation, Bonneville Power Administration, Portland, Oregon, September 1981.

2. Elrich and Lavidge Inc., Consultants, The Pacific Ilorthwest Residentlal Fnergy Survey, July 1980 .

3. 11.11. Sherman and D.T. Grimsrud, Mleasurement of Infiltration Using Fan Pressurfzation and Weather Data," Lawrence Berkeley Laboratory, LBL-10857, October 1980 .

4. D.L. Krinkel, D.J. Dickeroff, J. Casey, and D.T. Grimsrud, "Pressurlation Test Results: Bonneville Power Adginistration Fnergy Conservation Study," Lawrence Berkeley Laboratory Report, 'LBL-10996, December 1980 .

5. J.V. Berk, R.A. Young, S.R. Brown, and C.D. Hlollowell, "Impact of Energy-Conserving Retrofits on Indoor Alr Qualfty 1n Residential Housing," Lawrence Berkeley Laboratory Report, LBL-12189, Jamuary 1981 .

6. J.R. Dickinson, D.T. Grimsrud, D.L. F.rinkeI, and R.D. Lipschutz, "Results of the Bonneville Power Adminfstration Weatherization and Tightening Projects at the lidway Substation Residential Community," Lawrenci Berkeley Laboratory LBL-12742, January 1982 .

7. Energy Ffficfent Bufldings Program, Chapter from Energy and Environinent Diviston Annual Report 1980, pp 4-57 to 4-61, Lawrence Berkeley Laboratory, LBL-11985, Ilay 1981 .

8. J.V. Berk, C.D. Hollowe1l, J.ll. Pepper, and R. Young, "Indoor Air Ouality Ieasurements in Energy-Efficient Resfdential Bufldings," Lawrence Berkeley Laboratory, Play 1980.

9. W.W. Ilazaroff, M.L. Boegel, and A.V. Ilero, "leasuring Radon Source Yagnitude in Residential Buildings, Lawrence Berkeley Laboratory, August 1981 .

10. A.V. llero, "Alrborne Radionuclides and Radiation in Buildings: A Review," Lawrence Berkeley Laboratory, LBL-12948, August, 1981, and private communication.

11. B. Peterson, "Fleld Surveys of Phosphate Slag Used for Construction Purposes in Idaho Springs, Idaho," Idaho Department of llealth and Welfare, June 1979.

12. "Indoor Pollutants," Hatlonal Academy of Sciences, Ilational Academy Press, Washington, D.C. 20418, 1981 .

12a.A.V. Hero, "Indoor Radiation Exposures from Radon and Its Daughters: A Vlew of the Issue," Lawrence Berkeley Laboratory, LBL-10525, August, 1981 . 
13. J.R. GIrman, H.G. Apte, C.W. Traynor, and C.D. Hollowell, "Pollutant Erisglon Rates from Indocr Combustion Appliances and Sidestream Cigarette Smoke," Lawrence Berkeley Laboratory, LBL-12562, Uovember 1981 , submitted to Fnvi ronment International.

14. P.A. Breysse, "Formaldehyde Exposure Followlng Urea-Formaldehyde Insulation," Environ. Health Safety llews 26, (1-12), 1978.

15. C.D. Hollowell, et al., "Buflding Ventilation and Indoor AIr Qual1ty," Lawrence Berkeley Laboratory Report, LBL-10391, Jamuary 1980.

16. Ibid.

17. R.D. LApschutz, J.R. Girman, J.B. Dlcklnson, J.R. Allen, and C.H. Traynor, "Infiltration and Indoor A1r Quality in Energy Efficient Houses in Eugene, Oregon," Lawrence Berkeley Laboratory Report, LBL-1 2924, August 1981 .

18. F.J. Offermann, J.H. C1man, and C.D. Mollowe11, "lidway House Tightening Project: A Study of Indoor Alr Quallty?" Lawrence Berkeley Laboratory, LBL-12777, Hay 1981 .

19. "Formaldehyde and Other Aldehydes," Ilational Research CounctI, Committee on Aldehydes, Tlational Academy Press, Washington, D.C., 1981 .

20. Same as Reference 12 .

21. W.A. Cote, W.A. Wade, and J.F. Yocum, "A Study of Indoor Atr QualIty, Final Report," U.S. Environmental Protection Agency Report to. EPA-650/4-74-042, Washington, D.C., U.S. Environmental Protection Agency, 1974 .

22. Same as Reference 15 .

23. Same as Reference 15 .

24. G.W. Traynor, M.G. Apte, J.R. Girman, and G.D. llollowell, "Indoor Afr Pollution from Domestic Combustion Appliances," In 1981 Internat1onal Gas Research Conference Proceedings, September $2 \overline{8-0 c t o b e r ~ 1, ~}$ 1981, Los Angeles, CA; Covernment Institutes, Inc., Rockville, ID.

25. Ib1d.

26. G.W. Mraynor, J.R. Allen, M.C. Apte, J.F. D111worth, J.R. Girman, C.D. Hollowel1, and J.F. Koonce, Jr., "Indoor Afr Pollution From Portable Kerosene-F1red Space lleaters, Wood-Burning Stoves, and Wood-Rurning Furnaces," Lawrence Berkeley Laboratory, LBL-14027, Plarch 1982 .

27. Same as Reference 13 .

28. B.R. Hubble, J.R. Stetter, E. Gebert, J.B.L. Ilarkness, and R.D. Flotard, "Experimental Measurements of Emissions from Residential Wood-burning Stoves," in Pesidential Solid Fuels: Fnvironmental 
Impacts and Solut1ons, Oregon Graduate Center, Beaverton, Oregon.

29. D.J. Moschandreas, J. Zabransky, and H.E. Rector, "The Effects of Woodburning on the Indoor Residential A1r Quality," Environment International, Vol. 4, pp 463-468, 1980.

30. Same as Reference 26.

31. B.J. Ferris, ex a1., "Effects of Sulfur Oxides and Resp1rable Part1cles on Human Hlealth," Am. Rev. Resp1r. D1s. 120: 767-779, 1979.

32. H.D. Lebow1tz and B. Burrows, "Resp1ratory Symptoms Related to SmokIng Habits of Family Adults," Chest 69 48-50, 1976.

33. J.D. Spengler, et al., "Long Term Measurements of Respirable EuIfates and Particles Inside and Outside llomes," Atmos. Environ. 1.5: 23-30, 1981 .

34. J.L. Repace and A.ll. Lowrey, "Indoor A1. Pollution, Tobacco Smoke, and Public Health," Scfence, Vo1. 28, pp 464-472, May 2, 1980.

35. J.D. Spengler, et a1., "Personal Exposure to Resp1rable Particles," Paper 80-61.5b, presented at the 73rd Annual tleeting of the Air Pollution Control Association, June 22-27, Montreal, Quebec, 1980.

36. U.S. Department of Healch, Education, and Welfare, Public thealth Service. "Smoking and Health, A Report of the Surgeon Ceneral," DHEW Publication Ilo. PHS 79-50066, Washington, D.C., U.S. Government Printing office, 1979.

37. C. Florey et al., "The Relation between Resp1ratory Illness in Pr1mary Sctwol Children and the Use of Gas for Cooking," Int. J. Fpidem101. 3: $347-353,1979$.

38. R.J. Hella et al.., "The Relation between Regpiratoty Illness In Primary School Children and The Use of Gas for Cooking," Int. J. F.pidem101 8: $333-338,1979$.

39. M.D. Keller et al., "Respiratory Illness in Households Using Cas and electricity for Cooking," Enyiron. Res. 19: 495-503, 1979.

40. F.E. Spelzer et al., "Respiratory D1sease Rates and Pulmonary Function in Children Associated with $\mathrm{HO}_{2}$ Exposure," Am- Rev. Respir. D1s. 121: $3-10,1980$.

41. National Research Gounc11, Committee on Pledical and Blolggic Effects of Envi ronmental Pollutants, "Carbon Plonoxide," Washington, D.C. Itational Academy of Sclences, 1977.

42. Bloastronautics Data Book, Hational Aeronautics and Space Administration, IIASA - SP 3006, Washington, D.C. 1973. 
43 F..F. Schaefer, "A Concept of Triple Tolerance Limlts Based on Chrontc $\mathrm{CO}_{2}$ Toxtctty Studtes," Aerogpace Hed. 32: 197-204, 1961.

44. H.S. Coromosov, "The Physlological Basis of Mealth Standards for Dwellings," PliS 33 (1968) published by W.I.0., Ge.reva.

45. A1r Ọality Criterla for Particulate latter, Ilational A1r Pollution Control Association, Publication Ho. AP-49.

46. S. Budiansky, "Indoor A1r Pollution," Environmental Sclence and Sechnology 14: 9, September 1980.

47. T. llirayama, "llon-Smok1ng Wives of Heavy Smokers Have a IIgher Risk of Lung Cancer: A Study from Japan," Br. lled. J. 282: 183-185, 1981.

48. I.J. Selikoff, "Asbestos," Environment II: 2 (March 1969).

49. R.L. Dimmick and H. Wolochow, "Affecis of Energy Conservation leasures on Air Hyglene In Public Bulldings: Final Report," Lawrence Berkeley Laboratory, LBL-10553, February 1980. 


\section{IYTOOR AIR QQUALITY CONTROL TECHNIOQUES}

\section{A. Introduct1on}

Indoor afr quality control techniques can be divided into the following three general categorles: (1) techniques that reduce or remove pollutant sources, (2) ventilation, and (3) alr cleaning. This section contains an introduction to each category of control techniques followed by a discussion of techniques that may be sultable for controlling Indoor levels of radon, formaldehyde, and combustion products. Control techniques that are not sultable for a weatherization program, such as exclusion of bullding materials, are not considered here. In addition, techniques that. appear too expensive for a weatherization program, even if they may te suttable In other situations, are mentioned only briefly. Avallable data describing the effect of each control technique on indoor pollutant concentrations is summarized. A simple model for estimating the effect of a control technique on indoor air quality is presented in Appendix B.

\section{B. Source Control}

The sources of Indoor alr pollutants can be removed from the residence, fsolated from the 1ndoor a1r, or modifled so that the rate of pollutant emission is decreased. Removal of pollutant sources is advantageous because it is a permanent, effective measure and because no future maintenance or operating costs result; however, the sources must be Identified before they can be removed. In addition a substicute for the removed item 18 generally required and the initial cost, operating and maintenance costs, and performance of the substitute should be considered. Some methods of 1solating pollutant sources from indoor alr involve ventilation and are discussed in the section on ventilation control techniques.

\section{Radon Source Control}

Removal of radon (Rn) sources Involves the removal and replacement of concrete, masonry, or brick bullding materials or removal of the soll surrounding the basement, slab floor, or crawlspace. Removal of these materials is generally undertaken only when the materials have a high radium content due to contamination by mining or industrial processes. These techniques have been used successfully in a few homes with very high radon levels but appear too expensive for a weatherization program. Tap water from wells can be a significant source of radon. In such cases a switch to a water supply that is low in radon will reduce indoor radon levels. Aeration or storage of the water prior to its entry into the residence are other possible control measures.

The principal means of reduclng the transport of radon to bullding interiors are to seal materials having significant emanation rates or, for the more common case of transport from surrounding soll, to plug cracks or holes through which air with a high Rn content (1.e., soil gas) moves. Materials may be sealed by epoxtes or other coatings with 
up to 90 percent effectiveness. ${ }^{1-4}$ Filling holes with impervious materials, stopping transport by installation of plastic or other barrlers, or sealing surfaces has proved effective in some cases that required remedial action (see, for example, references 5 to 7 ), but all require integrity of the barrier for long-term transport reduction. The general applicability or effectiveness of these measures as long-terw passive controls is not known. (It should be noted that confinement of radon by diffusion or convection barriers results in a bulldup of radon and 1 to daughters behind the barrier, causing an increase In gamms 1rradiation from bullding materials. This increase appears less gignificant than the assoclated decrease in alrborne radon and daughters.

Further study of the mechanism and location of radon entry into residences should probably precede efforts to 1solate radon sources from the Indoor atr.

\section{Formaldehyde Source Control}

Removal and replacement of bullding materials that emit formaldehyde Is a potential control measure but is generally expenstve.

In laboratory studies ${ }^{9-11}$, varlous paints, lacquers, varnishes, and vinyl papers have significantly reduced the rate of formaldehyde emission from particleboard. Some of these coatings conta1n substanses that react with formaldenyde, thus preventing its release into the surrounding atr. The effectiveness of surface costings, when applied to the exposed surfaces of Installed particleboard, is not well known.

Ammonia fumigation and dehumidification are two promising techniques for reducing the rate of formaldehyde emigsion from butlding materials. In the armonta fumigation technique, ammontum hydroxide is placed in shallow pans in every major room of the residence. The home is sealed for at least twelve hours while fans circulate the Indoor aff and the indoor temperature is maintained at $27^{\circ} \mathrm{C}$ or higher. Jevell ${ }^{12}$ used chis technique in twelve moblle homes and reported 45 to 90 percent inftial reduct lons in formaldehyde levels and 39 to 81 percent reductions in fur homes monttored after a 40 to 60 week perlod. Further work is needed to obtain additional long term data on the effectiveness of this technique.

Dehumidification is another potentlally useful technique for reducing the rate of emlssion of formaldehyde from bullding materlals. Birge et al. report results of recent tests in a climate-controlled chamber contalning particlebaard. The tests indicate a 17.5 percent decrease in formaldehyde levels for every 10 percent reduction in relative humidity. (The authors assumed a linear relation between formaldehyde level and relative humidity; however, thelr results are reported only for two relattve humtdities,) Simtlar experiments perforwed by Anderson et a1. 14 , but at several humiditles, Indicate a Iinear relation between Formaldehyde concentration and humidty ratio (1.e*, mass of water vapor/mass of a1r). In their studies, when the chamber temperature and a1r change rate were maintained at $22^{\circ} \mathrm{C}$ and 0.5 a1r changes per hour, respectively, a decrease in relative humidity from 70 to 30 percent caused a 50 percent decrease in formaldehyde levels. 
A study by Long et al. 15 Indicates that the release of tormaldehyde from urea-formaldehyde foam insulation is also reduced when humidity is lowered.

No studies have been performed in actual homes to determine the effect of dehumidification on indoor formaldehyde concentrations. Also, It is possible that dehumidification may slow the rate of formaldehyde emission from materials but not decrease the total awount of formaldehyde emitted. The avallable chamber studies Indicate, however, that dehumldification may cause reductions in formaldehyde concentrations sufficlent to counteract or partlally counceract the moderate increases typlcally expected from a weatherization program. (Weatherization measures may increase indoor formaldehyde levels by decreasing infiltration and also indirectly by causing increases in indoor humidity levels). Dehumidification can be accomplished by employing residential dehumidiflers, by local ventilation near humldity sources (e.g., use of bathroom fans that exhaust to outside), or by providing ventilation with outdoor alt when the outdoor alr is less humid than indoor alr.

While dehumidification may be a useful technique for reducing indoor

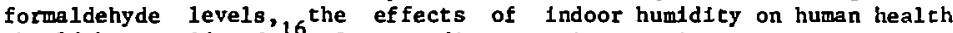
should be considered. 16 Some studies assoclate an increase in resplratory 1llness with reduced humidity levels. On the other hand, increased humldity may promote the growth of molds, fungus, and house dust mites which cause allergic reactions in some individuals.

Combustion Product Source Control

Removal of unvented combustion appliances (e.g., gas stoves, unvented space heaters) is an obvious technique for eliminating their emission of combustion products into the indoor afr. When evaluating removal of an unvented appliance, the inttial, operating, and maintenance costs for the substitute appliance plus the form of energy used by the substitute appliance (e.g*, natural gas or electricity) should be considered and compared to the benefits of the weatherization program. As discussed below, local ventilation may service adequately to vent products frow some combustion appllances, gas stoves in particular. (The removal of unvented combustion appliances with no specific ventilation may be desirable from a health standpolnt, even if no weatherization measures are Implemented.) Vented combustion appliances can be a significant source of indoor pollutants if they perform improperly (e.g., If a furnace has a cracked heat exchanger) or if the vent system does not work properly. In such cases, repair or replacement of the appliance or vent system is approprlate, independently of the weatherization program.

\section{Ventilation Control Techniques}

The :eplacement of Indoor alr with outdoor alr (i.e. ventilation) is the mont common method of reducing the levels of indoor generated air pollutants. Ventilation can be local or distributed, perfodic or continuous, natural or mechantcal, and with or without heat recovery. A significant advantage of ventilation is its ability to reduce levels of 
all Indoor alr pollutantg if the outdoor concentrations are less than the indoor concentrations; 18 however, ventilation is more effective for some pollutants than for others. A few studies have suggested that Increasing the ventilation rate is only partially effective in reducing formaldehyde levels because high ventilation fates increase the rate of formaldehyde emission from bullding materials. 13, 14, I9 The Increase in formaldehyde emission rate, however, may cause a decrease in the time period over which Bigfificant formaldehyde emissions occur. Models for Indoor air quality ${ }^{20}$ indicate that increased ventilation wil cause a smaller decrease in the concentration of a reactive air pollutant than the level of a non-reactive pollutant. (Examples of reactive pollutants are nitrogen dioxide, formaldehyde, and some particulates that are removed from indoor air by interaction with indoor surfaces.) The reduction in Indoor pollutant concentration due to an increase in ventilation rate can be estimated using the model presented in Appendix B. Disadvantages of ventilation as a control technique are ( 1 ) it may cause an Increase in Indoor levels of outdoor-generated alr contaminants, (2) it generally increases heating or alr conditioning loads, and (3) mechanical ventilation equipment has significant inftlal, operating, and malntenance costs.

Mechaulcal ventilation with heat recovery, local ventilation of gas stoves using an exhaust hood (that exhausts to outside), and natural or mechanical ventilation of crawl spaces are control techniques that may be suitable for a weatherization program, and each is discussed below.

Mechanical Ventilation wth Heat Recovery

Residentlal heating and/or cooling loads can be decreased by reducIng natural infiltration and substituting mechanlcal ventilation with heat recovery. The most common method of residential mechanical vent1lation with heat recovery is the use of a residential air-to-air heat exchanger. The heat exchanger provides a controlled amount of ventilatIon that counteracts the adverse effects of reduced infiltration. In addition, the heat exchanger recovers much of the energy that would be lost when ventilation occurs by alr infiltration.

Fleld studies by offerwann et al. 17 have demonstrated the effectiveness of alr-toratr heat exchangers in reducing indoor pollutant concentrations. In their study, alr exchange rates and indoor and outdoor pollutant concentrations were measured in nine homes for a ten day period without mechanical ventilation through an alr-to-air heat exchanger, followed by a ten day period with mechanical ventilation through a heat exchanger. The average Increase in alr exchange rate, as deterulisd by tracer gas decay measurements, was $80 \%$ (from 0.35 to 0.63 afr changes per hour). During the perlod of heat exchanger operation, average indoor radon concentrations decreased 50\%, average indoor formaldehyde concentrations decreased $21 \%$, and average indoor relative humldity fell from $39 \%$ to $35 \%$. Because the houses in this study did not have significant sources of nitrogen dioxide $\left(\mathrm{NO}_{2}\right)$, the outdoor concentrations of $\mathrm{NO}_{2}$ were higher than indoor concentrations, and operation of the heat exchangers caused a slight increase in Indoor $\mathrm{NO}_{2}$ levels. The increases in lndoor $\mathrm{NO}_{2}$ concentrations were only a few parts per billion. (llowever, operation of a residential heat exchanger, can sometimes cause a 
significant Increase in the Indoor concentration of an outdoor air pollutant. For instance, one howeowner in the study shut off the heat exchanger each evening because swoke, presumably from nelghbor's fireplaces, was brought into the house by the heat exchanger.) Particulate concentrations were measured $1 \mathrm{n}$ two of the houses studied and decreased approximately $30 \%$ when the heat exchangers were operated. A longer term study might have indicated different reductions in Indoor pollutant concentrations because the pollutant source strengths may have changed throughout this study. In addition, the degree to which pollutant concentrations are reduced depends on the amount of ventilation provided, the wethod of heat exchanger installation (1.e., the characteristics of the duct system used with the heat exchanger), and on the location(s) of pollutant sources.

Laboratory tests by Fisk et al. 21,22 indicate that heat exchangers can preheat or precool ventilation air by 45 to 85 percent of the difference between Indoor and outdoor temperatures and show variations in fan power consumption $f_{5}$ om 0.4 to 2.1 watts per $\mathrm{m}^{3} / \mathrm{hr}$ of ventilation supplied. F1sk and Turiel ${ }^{23}$ have evaluated the energy savings attributable to the use of heat exchangers in new homes and have also performed a cost-benefit analysis for heat exchangers based upon the point of view of the homeowner. They compared the energy consumption and energy costs for a cypical house to that for a house with low Infiltration and supplementary ventilation provided through a heat exchanger. Cost effectiveness was determined to be highly affected by heat exchanger performance, climate, type of heating fuel, and the amount of ventilation supplied by the heat exchanger. Discounted payback periods ranged from 5 to over 30 years and net present benefit ranged from $-\$ 1358$ to $\$ 2425$ if a 20 year life for the heat exchanger was assumed.

Most models of residential heat exchangers are used with a system of ductwork for air distribution; however, some models are simply installed through the wall or window of a residence much like a window alr conditioner. The window- or wall-mounted units may be more sultable for use in a weatherization program because their initial and Installation costs are lower and because they are designed to provide a small amount of ventilation consistent with the reductions in infiltration expected from a weatherlzation program. Additional studies of window- or wall-mounted heat exchangers are needed. Studies supported by the Bonneville Power Adminlstracion are currently underway at Lawrence Berkeley Laboratory to determine how effectively these units ventilate a residence. All currently avallable window- or wall-mounted heat exchangers are designed co transfer molsture, as we 11 as heat, between airstreams; therefore, some contaminants may also be transferred between airstreams in these models. Before these units are employed on a large scale, a study of contamlnant transfer rates should be performed. If contaminant transfer is found to be a problem, relatively simple modifications may be adequate for reducing the rate of contaminant transfer. Finally, the econonics of residential heat exchangers should be evaluated for the case of a retrofit program and this evaluation (also supported by the Bonneville Power Administration) is undezway at Lawrence Berkeley Laboratory. 
A second method of providing mechanical ventilation with heat recovery involves the uea of exhaust air heat pumps. For this technique, a fan draws outcoor air into the house and exhausts indoor alr through a small heat punp. The heat pump generally transfers energy from the outgoing alr to the domestlc hot water supply; however, heat pumps that transfer energy to the indoor air are possible. Exhaust air heat pump systems are gaining popularity in Sweden ${ }^{24}$ but have not yet. been utilized in the United States. An advantage of exhaust heat pumps, when compared to heat exchangers, is that a system of ductwork is not required to distribute incoming alr. In some cases, however, depressurIzation of the house, caused by operation of an exhaust ventilation system, may Increase the flux of radon into the Indoor air.

Exhaust Iloods for Gas Stoves

Gas stoves are a concentrated and periodic source of Indoor air pollutants. The entry of these pollutants into a residence can be reduced by providing local, periodic ventilation with a range hood. Operation of a range hood caused 60 to $87 \mathrm{z}$ reductions $1 \mathrm{n}$ the amount of $\mathrm{CO}, \mathrm{CO}_{20}$ and $\mathrm{NO}_{x}$. that entered a research house in a study by Traynor et al. In their study, the flow rate of air exhaustel through the range hood was varted from 150 to $420 \mathrm{~m}^{3} / \mathrm{hr}$. A range hood w1th exhaust rates of 120 to $400 \mathrm{~m} / \mathrm{hr}$ caused 40 to 50 reductfons in average incremental $\mathrm{NO}_{2}$ levels in a study by Macriss and Elkens. ${ }^{25}$ (Average Incremental $\mathrm{NO}_{2}^{2}$ level is the Increase in average $\mathrm{NO}_{2}$ level due to operation of a gas stove.) The performance of range hoods may depend on design variables and method of Installation; however, avallable studies indicate that range hoods are effective in removing gas stove combustion products. Range hoods w111 not be effect lve if they are not used by the homeowner, so studies of usage patterns or automatic range-hood controls may be required.

Craw1 Space and Basement Vent1lation

Natural or mechanical ventilation of crawlspaces or basements that are 1solated from the remainder of the house is a potentially sulcable method for reducing the transport of radon into the indoor alr. Crawlspace ventilation has been employed in some Canadian communities but has not been Investigated in a systematic manner.

D. Alr Cleaning Control Techniqueg

The term "alr cleaning" refers to methods for the removal of pollutants from indoor alr. A1r cleaning methods that may be sultable for controlling Indoor pollutant levels include filtration, electronic a1r cleaning, Ionization, abeaption, adsorption, and atr circulation. Each general method of air cleaning is described briefly here; however, more decalled information is avajiable in references on al $\Sigma$ pollution control techniques. 26-30 Following each description, the suitability of each method for the control of indoor air pollutants is discussed. As a class, afr cleanling techniques w111 generally not increase residential heating loads, although significant electrical energy may be required to operate the equipment. All energy consumed for alr cleaning will generally be delfvered to the residence, thus reducting loads on heating 
systems but lacreasing loads on air conditioning equipmeat.

Filtration, Electronic Alr Cleaning, and Ionization

Technical Description

Alr cleaning by filtration is accomplished by passing the air through a filter which 18 usually constructed irom a woven fabric, a paper materlisl, or a flbrous matt. Filters are designed for tbe removal of particulates or mists and are generally not effective in removing gaseous contaminants. The performance criterla for filters are particle collection efficiency (which varies with particle size), air flow resistance, and particulate capacity (1.e., fllter lifetime). High efficlency filters can remove almost 100 percent of particles as small as $0.3 \mu$; however, the fibrous matt filters typically used in residential furnace systems are not effective in removing submicron size parciculates, which are of primgry health concern. Filter systems with a wide varlety of efflciencles are comerclally avallable. Recently, filter materials that contaln fibers with a permanent electrical charge have been developed. These filters may be more sultable than conventional filters for the removal of small particulates. Filters must be perlodically cleaned or replaced, and sigalficant trade-offs exist between filter cost, collection efficiency, capacity, and alr flow resistance.

Electrostatic precipitators (one type of electronic alr cleaner) can be highly effective in removing even sub-micron particulates, but they are generally not effect Ive In removing gaseaus contaminants. An advantage of precipitation over filtration is that small particles can be ramoved without imparting a large pressure drop to the airstream. (A large pressure drop leads to a high fan power consumption.) Also, preclpitator collection surfaces are generally cleanable while high efficlency filters must usually be replaced. In an electrostatic precipitator, particles are first charged by gaseous tons produced by an electrical corona. The charged particles then pass through an electric field and are attracted to and collected by an oppesitely charged electrode. The collection surfaces must be cleaned periodically. Some precipitators and other types of electronic alr cleaners produce a small amount of ozone and many units are supplied with replaceable charcoal filters to remove the ozone and odors. Residential sized precipitators are readily avaflable for installation in furnace ductwork or as portable models. Collection surfaces are usually cleaned with soap and water; in some models they can be cleaned in an automatic dishwasher.

Two additional types of electronic afr cleaners are available commercially, A charged-media nonionizing electronic alr cleaner consists of a dfelectric filtering medfum (e.g., glass fiber matt or cellulose matt) that is in contact with a grid of alternately grounded and charged members. The electrostatic fleld created in the dielectric filter medium causes approaching particles to be polarized and attracted to the filcur. The filtering medium must be replaced perfodically. A similar device, the charged-media lonizing electrontc afr cleaner uses a corona discharge to charge the particulates (as In an electrostatic precipitator) and collects the particulates on a charged-media filter matt. 
Alr fonizers produce negative lons, which can attach to particulates. Ionizers generally have no collection surface; therefore, the particulates must attach to sope indoor surface if they are to be removed from the alr. Iontzers generally rely on natural movement $u$ alr to bring particulates near the lonization source. The performance and usefulness of lonizers is presently a controversial topic.

Impact on Indoor A1x Quality

Particulates produced by gas stoves ang siggstream clgarette smoke are almost entirely sub-micron in size. 31,32 These particles can be removed by very high efficlency filtero but are probably more economically removed by electrostatic prectpitators or other electronic air cleaners. The quantity and size distribution of particulates that enter fndoor alr from fireplaces and wood stoves have not been determined. Electrostatic preclpitators should be effective in renoving those particulates, however, even if they are very snall. Usage patterns for electronlc alr cleaners and filters are important because neither device will perform properly if it is not maintained.

The effect of filtration and electronic a1r cleaning on radon daughter levels 3 and $_{34}$ the assoclated radiation dose is complex and not fully understood. 33,34 Each device will remove radon daughters that are attached to the particulates they collact. In addition, each device way reqove some of the unattached radon daughters (1.e., daughters that are not attached to particulates) through electrostatic collection or other physical or chemtcal processes. One would expect these devices to reduce radiation doses because they reduce radon daughter levels and, in many cases, this may Indeed be true. If Indoor particulate concentratlons are reduced to low levels, however, the result may be an increase In the concentration of radon daughters that are not attached to particulates because of the reduced frequency of interaction between radon daughters and particulates. According to some models of radiation dose to the lungs from radon daughter Inhalatiog, unattached daughters cause a much higher dose than atcached daughters; ${ }^{35}$ therefore, f1Itration or electronic air cleaning may actually ou detrimental in some cases. An additional complicating factor in assessing the effect of these measures is that each weasure may, to an extent that ts not now known, increase the plate out (1.e., attachment) of unattached radon daughters on Indoor surfaces because of the reduced particulate levels or because fndoor afr movement is increased.

Elevaced particulace levels may be one of the most comwon indoor air quality problems; therefore, studies of the perforance of commerclally avallable particulate removal devices should be undertaken. Careful study is definitely need to evaluate the Impact of these devices on the levels of attached and unattached radon daughters.

\section{Absorption}

In absorption alr cleaning the objectionable gaseous contaminant is absorbed by a liquid from the a1r. The terms "scrubbing" and "air washfng" are commonly used to describe absorption processes. Typically the contaminanted air is passed through a liquid spray or over wetted 
surfaces. The pollutant can be removed only if it is soluble in the liquid or if it reacts chemically with the liquid. Water is the most commonly used liquid; however, In many cases some additive to the water is utilized. Some absorption equipment is effective in removing particulates as well as gaseous contaminants.

Absorption processes have recelved little consideration for the control of Indoor pollutant levels despite their common use for the removal of industrial alr pollutancs. An initial theoretical study of absorption processes for Indoor air quality control is underway at Lawrence Berkeley Laboratory. Absorption by water appears most promising for the removal of formaldehyde, because formaldehyde reacts rapidly with water. Various absorption processes are used 58 absorb nitrogen dioxide ( $\mathrm{NO}_{2}$ ) from industrially contaminanted afr. ${ }^{36}$ However the processes are complex and generally not sultable for indoor alr which has much lower concentrations of $\mathrm{NO}_{2}$. Absorptzgn of $\mathrm{NO}_{2}$ 1nto water may be possible if additives to the water are used ${ }^{37}$, but further study is needed. Absorption processes appear least promising for radon, whlch is essentially non-react Ive and only slightly soluble in water.

\section{Adsorption}

In adsorption afr cleaning, gaseous pollutants are adsorbed onto the surface of a solid. The exact mechanisms of adsorption are not fully underscood. Gases with high molecular weights are generally adsorbed more easily than gases with low molecular welghts. Materials used for adsorption typically have a very large surface area due to the existence of wicroscopic pores. The most commonly used adsorbents are activated carbon (activated charcoal), activated alumina, silica gel, and molecular sleves. In many cases, adsorbents are impregnated with a materlal that Improves their adsorption of a partlcular pollutant. of the four most commonly used adsorbents, only activated carbon is non-polar. Polar adsorbents preferentlally adsorb polar molecules; therefore they are usually Ineffective for cleaning of molst air because they become saturated with highly polar water molecules. Non-polar activated carbon is effective in molst airstreams because the water molecules are more highly attracted to each other than to the carbon surface. Adsorbents become saturated after a perlod of use and must then be regenerated or replaced.

The effectiveness of adsorbents in removing radon, radon daughters, and nitrogen dloxide from Indoor alr is got well known. Jewell and the Swedish Council for Bulldings Research ${ }^{38}$ have Investigated the use of Purafil (an aluminum oxide impregnated with potassium perwanganate) and found it effecifve in adsorbing formaldehyde from alr. Jewell reduced the levels of formaldehyde in a mobile home from approximately $500 \mathrm{ppb}$ to $140 \mathrm{ppb}$ by passing $2640 \mathrm{~m}^{3} / \mathrm{hr}$ of 1 ndoor aif through a $36 \mathrm{~kg}$ bed of Puraf 11 . (The alr circulation rate of $2640 \mathrm{~m}^{3} / \mathrm{hr}$ was equivalent to 13.6 alr changes per hour.j Netther JeweII nor the Swedish researchers present data on the 11fetims of the Purafil; however, the Swedish researchers indicated that Purafil systems misy be much more economical 
than ventilation through alr-to-air heat exchangers.

\section{A1r Circulation}

A1r circulation or air movement to not generally considered an air cleaning method; however, it may increase the rate at which some contamInants are removed by attachment to indoor surfaces. Radon daughters, reactive gasses, and particulates are most likely to be removed by this technique. Vazarof ${ }^{39}$ observed a substantial decrease in radon daughter levels from operation of a furnace fan. The furnace's ventilation systell did include a furnace filter; therefore, operation of the furnace fan caused both air filtration and air circulation. Because nitrogen dioxide, formsldehyde, and some particulates react with bullding surfaces, alr-circulation may also cause decreases in their levels.

E. Discussion of Control Techniques

A large number of techniques are potentially suitable for the control of Indoor alr pollutant levels. The cost and effectiveness of these techniques is generally not well known; therefore, further research is needed before most techniques are wldely utilized. Based upon available information, the following control techniques appear most promising for use in a weatherization program:

1. Mechanical ventilation with heat recovery - for reducing the levels of all alr contaminants if the outdoor levels are lower than indoor levels.

2. Ammonia fumigation and dehumidification - for reducing the rate of formaldehyde emission from bullding materials.

3. Removal of unvented combustion appliances.

4. Spot ventilation of gas stoves using an exhaust hood.

5. Crawlspace ventilation - for reducing the rate of radon entry into the indoor alr.

6. Electronic air cleaning and filtration - for removal of particulates and perhaps radon daughters.

7. Absorption of formaldehyde into water.

8. Adsorption of formaldehyde by Purafil.

9. Alr c1rculation - to increase the rate at which radon daughters and perhaps other contaminants attach to 1ndoor surfaces.

A mathematical model presented In Appendix B is useful for providing a rough estimate of the Impact of control techniques on Indoor air quality but further experimental dar. 18 needed to increase its ugefulness. 
The 1mpact of many control measures on the levels of 1ndoor pollutants depende on the size or capacity of the control system utilized. If too large a conkrol oystem is employed, Inftial and operating costs will be greater than necessary. In addition, the energy savings resultIng from a weatherization program can be sigaificantly compromised or even overwhelmed by energy requirements for the control measure, if too large a control system is utilized. On the other hand, the levels of Indoor air pollutants will not be reduced sufficlently if too small a control system is employed. Specifying the size or capacity of the control system will be difficult unless the impact of the weatherization ineasures on Infiltration is known. This Impact could be estimated on the basis of the weatherization audit, but the actual reduction in Infiltration 1s 11kely to vary significantly from house to house. Alternatively, the leakage area (a scale parametar for infiltration) of each house can be measured before and after weatherization using the fan pressurization techniques; and the results can be used to size the control system. The leakage area measurements may be accomplished during weatherization, if fan pressurization is utilized for the identification and sealing of atr leakage points.

Th1s section on Indoor alr quality control techniques, and the previous two sections, provide background Information for Part II of this report which describes a methodology for altering the exclusion list. 
1. Krieluk, E.M., Tarasov, S.I., Shamov, V.P., Shalak, I.I., Lisachenko, E.P., and Gomelsky, L.G., 1971, A Study on Radioactivity In Buflding liaterials, Leningrad Research Institute for Radiation Ilygiane, Leni ngrad.

2. Culot, M.V.J., and Schiager, K.J., 1973, Radon Progeny Contro1 in Bulldings, Colorado State University Report CoO- 2273-1.

3. Auxter, J.A., Shinpaugh, W.H., Kerr, G.D., and Ghristian, D.J., 1974, "Preliminary Studies of the Effects of Sealants on Radon Emanation from Concrete," llea1th Phys. 27, 390-391.

4. Culot, M.V.J., Schlager, K.J., and 0lsen, H.G., 1978, "Development of a Radon Barrier," llealth Phys. 35, 375-380.

5. Atomic Energy Control Board, Canada 1978, Workshop on Radon and Radon Daughters in Urban Communities Associated with Urantum Mining and Processing, Ellott Lake, Ontario, March 7-9, 1978.

6. Atomlc Energy Control Board, Canada, 1979, Second Warkshop on Radon and Radon Daughters in Urban Comminities Assoctaced with Uranium Mining and Processing, Bancroft, Ontario, March 12-14, 1979.

7. Atomlc Energy Control Board, Cziada, 1980, Third Workshop on Radon and Radon Daughters in Urban Commulties ABsociated with Uranium Minting and Processing, Port Hope, Ontar1o, Mach 12-14, 1980.

8. Culot, M.V.J., Schiager, K.J., and 0lson, H.G., 1976, "Prediction of Increased Gamma Fields After Application of a Radon Barrier on Concrete Surfaces," Health Phys. 30, 471-478.

9. Sudin, B., "Formaldehyde Emlssion from Particleboard and Other Buflding Materlals: A Study from the Scandinavian Countries," presented at the Particleboard Serles Symposium No. 12, Washington State University, April 4-6, 1978.

10. Roffael, E., "Progress in Elimination of Formaldehyde Liberation from Particleboards," presented at the Particleboard Series Symposium No. 12, Washington State University, April 4-6, 1978.

11. Malygina, "The Effect of Cladding and Additional Thermal Processing on Emission of Harmful Substances from Sheets Made of wood Shavings and Menufactured on a Base of Urea Resin," translated from Russian, pub11shed In C1giena 1 Sanitar1ya 39 (8):95, 1974.

12. Jewell, R.A., "Reduction in Farmaldehyde Levels In Mobile Homes - An Update," presented at the Adhesive and Sealant Counctl's 1981 Fall Semtnar, Philadelphia, Pennsyivanta, October 20, 1981.

13. B1rge, A., Mellegaard, B., flanetho, P., and Ormstal, E.B., "Formaldehyde Release from Particleboard - Evaluation of a liathematical Node1," Holz als Roh-und Werkstoff 38 (1980) 251-255. 
14. Anderson, I., Lunçquigt, G.R., and Molhave, L., "Indoor Air Polluilon Due to Chipboard Used as a Construction Material, "Atmospheric Environment, 9, 1121-1127, 1975.

15. Long, K.R. Plerson, D.A., Brennan, S.T., and Frank, C.W., "Problems Associated with the Use of Urea-Formaldehyde Foam for Residential Insulation, Part 1: The Effects of Temperature and Humidity on Formaldehyde Release from Urea-Formaldehyde Foam Insulation," Oak Ridge National Laboratory Report, ORNL/SUB-7559/I, September, 1979.

16. Green, G.Il., "The Positive and Hegative Effects of Bullding Humldification," ASIRAE preprint HO-82-9, No. 3, to be published in ASILRAE Transactions, 88 , pt. $\underline{1}, 1982$.

17. Offermann, F.J., Hollowe11, C.D., and Roseme, G.D., "Low Inf11tration Housing in Rochester, New York: A Study of Atr-Exchange Rates and Indoor A1r Quality," priesented at the International Symposium on Indoor A1r Quality, Amherit, Massachusetts, October 13-16, 1981, submitted to Enyironment International.

18. Nazaroff, W.W., Boegel, M.L., Hollowe11, C.D., and Roseme, G.D., "The Use of Mechanical Ventilation with Heat Recovery for ControlIIng Radon and Radon Daughter Concentrations In Houses," Atmospheric Environment 15, 263-270, 1981 .

19. Turiel, I., Hollowel1, C.D., Miksch, R.R., Rudy, J.V., and Young, R.A., "The Effect of Reduced Ventilation on Indoor Air quality in an office Building," Lawrence Berkeley Laboratory Report, LBL-10479, June 1981, to be published in Atmospheric Environment.

20. Traynor, C.W., Apte, H.G., Dillworth, J.F., Hollowell, C.D., and Sterling, E.M., "The Effects of Ventilation on Residential Air Pollution Due to Emissions from a Cas-Fired Range," Lawrence Berkeley Laboratory Report, LBL-12563, November 1981, submitted to Environment Internationa1.

21. Flsk, W.J., Roseme, G.D., and Hollowe11, C.D., "Performance of Residential A1r-to-Alr lleat Exchangers: Test Methods and Results," Lawrence Berkeley Laboratory Report, LBL-11793, September 1980.

22. F1sk, W.J., Acher, K.M., Boonchanta, P., and Hollowe11, C.D., "Performance Measurements lor Residential Alr-to-AIr Heat Exchangers," Lawrence Berkele; Laboratory Report, LBL-12559, November 1981, submitted to Environment International.

23. Fisk, W.J., and Turlel, I., "Residential A1r-to-A1r Heat Exchangers: Performance, Energy Savings, and Economics," Lawrence Berkeley Laboratory Report, LBL-13843, February 1982, to be submitted to Energy and Buildings.

24. Gezelius, G., "Soon There W111 Be 50,000 SEX-Ventilation Systems Installed in Single Family Ilouses in Sweden," summary 55:1981 SwedIsh Council for Bullding Research, Sankt Coransgaton, 66, 5-122 33, Stockholm, Sweden. 
25. Macriss, R.A., and Elkens, R.I., "Control of the Level of No 1 in the Indoor Environment," presented at the Fourth International Clean A1r Congress, Tokyo, Japan, May 16-20, 1977.

26. Stern, A.C., Englneer1ng Control of A1r Pollution, Academic Press, London, 1977.

27. Crawford, M., Atr Pollution Control Theory, McGraw H111, 1976.

28. Strauss, H., Industrlal Gag Cleaning, Pergamon Press, 1975.

29. Treyba1, R.E., Mass Transfer Operat1ons, McGraw $\pi 111,1980$.

30. American Soclety of tleating, Refrigerating, and AIr Conditioning Engl neers, ASllRAE llandbook and Product Directory - 1975 Equipment.

31. Traynor, G.W., Anthon, D.W., and Ilollowell, C.D., "Techntque for Determining Pollutant Emtssions from a Gas-F1red Range," Lawrence Berkeley Laboratory Report, LBL-9522, December 1981, submitted to Atmospheric Environment.

32. G1rman, J.R., Apte, M.G., Traynor, G.W., Allen, J.R., and Hollowell, C.D., "Pollutant Emission Rates from Indoor Combustion Appliances and Sidestream Cigarette Smoke," Lawrt ce Berkeley Laboratory Report, LBL-12562, November 1981, submitted to Environment Internatronal.

33. Nero, A.V., "Alrborne Radionuclides and Radlation 1n Bu1ldings: A Review," Lawrence Berkeley Laboratory Report, LBL-12948, August 1981, subultted to llealth Physics.

34. J .. n, N. and McLaughl1n, "A1r F1ltration and Radon Daughter Leve. Laboratory of Applied Physics I, Tecinical University of Denmark, 2800 Lyngby, Denmark, and Physics Department, University Co1lege, Dublin, Ireland, draft copy, submitted to Environment International.

35. Harley, N.H., and Pasternack, B.S., "Alpha Absorption Measurements Applied to Lung Dose from Radon Daughters," Health Physics, 23, pp. $771-782,1972$.

36. Tennessee Valley Authority, "Technical Assessment of No Removal Processes for Utilicy Application," prepared for the Electric Power Research Institute and the Environmental Protection Agency, EPRI AF-568, EPA-600/7-77-127, March 1978 .

37. Schwartz, S.E., and White, W.H., "Ktnetics of the Reactive Dissolution of the Nitrogen Oxides and Oxyacids in Aqueous Solution," Brookhaven National Laboratory Report, BNL 30178, Hovember 1981 .

38. Swedish Bullding Research News, Newsletter 1981:1, Swedish Counc1l for Buflding Research International Secretarlat, S:t Goranggaton 66, S-1 1230 Stockholm, Sweden. 
39. Ilazaroff, W.W., "A ResidentiaI Radon Daughter Monttor Based on Alpha Spectroscopy," Lawrence Berkeley Laboratory Report, LBL-10768, Nay 1980.

40. Traynor, G.W., Apte, M.G., Girman, J.R., and Hollowell, C.D., "Indoor Atr Pollution frod Domestic Combustion Appliances," in Proceedings of the International Gag Research Conference, Los Angeles, CA, September 28-0ctobor 1, 1981, Government Institute, Inc. Rockville, $\mathrm{ND}$.

41. Hero, A.V., Boegel, M.L., Hollowe1l, C.D., Ingerso11, J.G., and Nazaroff, W.W., "Radoz Concentrations and Infiltration Rates Measured In Conventional and Energy Efflclent Housing," Lawrence Berkeley Laboratory Report, LBL-13415, September 1981, submitted to Itealth Physics. 
$-46-$ 
The purpose of excluding some houses from use of the infiltrationreducing elements of the weatherization program was to assure that no significant impact would arise from increases in levels of indoor pollutants that could be caused by the modest decreases in air exchange rates caused by infiltration-reducing measures. In the absence of more complete information, this was assured by excluding tightening measures from those houses that have a substantlal chance of having higher-thana-erape (or higher than "acceptable") indoor pollutant concentrations. The houses excluded are those that could have larger pollutant input rates because of the presence, or possible prosence, of spectfic sources 0 of unfavorable characteristics with respect to pollutant transport I. $)$ the Interior.

The most significant excluded classes are those assocfated with potential radon sources (or transport fearures) and those having woodburning stoves. These excluded classes have a substantial ef fect on the success of the weatherization progran, as measured by energy savings, since (1) Infileration reduction constitutes one of the largest sources of energy savings, as well as one of the most cost effective elements of the program, and (2) most houses In the BPA area appear to be among the excluded classes.

The degree of potential energy saving is not the principal issue in this document, but the mere size of the excluded classes is important. Approximately half of the houses have an excluded understructure and half with full crawlspaces do not have the requlred ground cover. Moreover, It appears that as many as half the houses otherwise qualifying for the program have wood stoves. Even though there must be considerable overlap among these excluded classes, it is apparent that tightenIng measures are permitted in only about a quarter of houses qualifying for other parts of the weatherization program.

Because so large a portion of the housing stock is presently excluded from the infiltration-reducting elements of the weatherization program, the effectiveness of the program could be substantially enhanced by removal of some classes of houses from the exclusion list. Several different bases could be used, elther alone or in comblnation, for removal of excluded classes: (1) Original exclusion of the class may have been overly conservative; 1.e., on the basis of present information, It may be found that tightening of certain classes of houses on the exclusion list would, without other precautions, still cause no signiffcant impact. (2) Specific elements of the weatherization program Itself may be adequate to assure no significant Impact, or this burden may be assumed by parts of other programs that occur concurrently with the weatherization program. (3) The weatherfzation program may be followed by programs or determinations that effectively assume the burden of proof, provided these follow-up programs effectively determine where the weatherization program can cause deleterlous effects and provided reinedial action can be taken early enough to prevent significant effects.

There are three essential aspects to any of these approaches, or combinations thereof: (1) development of better information on sources In housing classes or Individual houses; (2) adoption of criteria on acceptable individual or average concentrations; and (3) 1mplementation 
of mitigation measures (elther concurrently or retrospectively) in houses (or classes of houses) that require 1t. (Improvements in these respects are also useful independently of changing the exclusion 1ist.) There may, of course, be houses that are retalned on the exclusion IIst after consideration of anticlpated pollutant concentrations, potentlal effects, and avatiable mitigation measures. It is also concelvable that classes on the ixclusion 11 st may be altered, decreased or increased.

Because there are a number of grounds for removal of a class from the exclusion $118 t$ and - furthermore - each of these grounds may involve a number of possible elements, a methodology for renoval of classes is likely to have $a$ complex structure, with removal of various classes occurring over a period of time and dependent on successful implementation of program elements that provide a basis for their removal. Before proceeding to the formulation of a methodology, we indicate in section 4 the expected concentration distribution in housing classes on the exclusion list and the anticlpated effect of infiltration reduction. In section 5 we examine in more detall the generlc considerations for a methodology, specifically the conditions that permit removal from the list (or Indicate additions) and the context in which these changes may occur. Finally, in section 6 we delineate the framework in which housIng classes may be removed from (or, in principle, added to) the excluBion list with no significant impact on the populations living in these structures. 
The several exclusion criteria of appendix $E$ of the Fnvironmental Assessment are based on the presumption that certain house characteristics may, in sone circumstances, Increase the "source magnitude" for corresponding pollutant classes. The houses included in the program are, according to BPA's Revised Environmental Assessment, "those residences in which major sources of 1 ndoor air pollutants are minimized."

By the "source magnitude," we mean in this context the rate at which the pollutant in question is entted, by whatever means, into the house intertor. (For practical purposes, the source magnitude is of ten taken to be the rate per unit house volume; $-\rho^{\cdot g} \cdot{ }_{1}$ for radon, the source magnitude could be given in units of pC1 $h^{-1} 1^{-1}$ plcocurle per hour per liter.) The source magnitude therefore depends both on the rate at which the substance of interest is produced from local sources and on the avenues for entry into the alr inside the house. Furthermore, the source magnitude can, in principle, be reduced by controlling either the production rate or the efflciency of entry. The indoor concentration may, of course, also be controlled by ventilation or air cleaning.

Although the exclusion criterla are associated with specific source characteristics (elther production or entry), they only indicate a potentlal for higher-than-average source magnitudes or, ultimately, indoor concentrstions. In fact, in some cases, as Indicated below, the exclusion criteria as formulated do not pertain to the primary factors that may cause higher-than-average source magnitudes; in such cases, the stated criteria tend only to modulate the magnitude to a secondary degree. In other cases, the criterla as stated are specifically associated with higher-than-average source magnitudes, but measures may be taken to 1dentify that portion of the excluded class that suffers from. such difficulties, after which mitigation of one kind or another may be advised.

Considering these 11mitations of the exclusion criteria, we turn briefly to the various excluded classes to comment on the degree to which higher-than-average source magnitudes or indoor concentrations may. be expected to be assoctated with each class. For convenience, we group the excluded classes by poliutant of interest, treating first the classes associated with potentlally high radon source magnitudes (1.e., foundation design, household water source, and interior masonry) then turning to combustion appliances, primarily wood stoves, and to use of urea-formaldehyde foam insulation.

\section{A. Radon Exclusion Classes}

The three radon-related criterla are associated, roughly in the order siven, with vhat are thought to be the major sources of radon Indoors. In the Unfted states, radon entering the house from under and around the foundation is thought to be the most Important contributor to Indoor radon. In some cases, however, radon from household water that 1s drawn with little holdup from groundwater - e.8., via a private well - can contribute gubstantially to indoor radon concentrations. Finaily, 
In some circumstances, buflding materials that have unusually large radium concentrations can contribute significantly to indoor radon lev2ls, ordinarily only in the unusual case that radium-bearing industrial waste products are used in the manufacture of bullding materials.

For the more usual case of bullding materials (such as concrete aggregate or rock) drawn from local sources, the material underlying the house (if it has radium content olmilar to the bullding materials) will ordinarily constitute a more Important radon source, at least in houses with concentrations exceeding $1 \mathrm{pCi} / 1$ or so, largely independently ot whether or not the house his a ventilated crawlspace. That is, the major factor affecting the radon source magnitude is the radium concentration in the ground and rocks in the area; this concentration affects the degree to which underlying boll, household water, and local butlding materials contribute to indoor concentrations.

If local sources have low radon emanation rates, then the radon source magnitude for houses is small, and the presence or absence of one of the exclusion factors is of little importance, since the indoor concentration will be 1 ow in any case. (This fact will be eritically important in section 6 for frauling an approach to renoving classes from the exclusion list.) On the other hand, if radon concentrations, and hence source magnitudes, are high, this is likely to occur because local sources have high emanation rates, affecting virtually all houses in the area (albeit to a degree that depends on the particular house).

In the United States, the full range of radon concentrations observed Indoors exceeds a factor of 100 , and is probably closer to a factor of 1000 , $1 . e .,<0.1 \mathrm{pC} 1 / 1$ to something above $50 \mathrm{pCl} / \mathrm{s}$, even excluding the cases where spectal materials are used in the structure. Based on what is known now about the BPA area (e.g., measurements in Eugene, Oregon and Butte, liontana) a similarly large range occurs in this widely-varying region.

Because the exclision criteria as now framed do not relate directly to the question of whether local sources are high in radium content, the distribution of concentrations in houses excluded on the basis of these criteria is likely to have the same general appearance as the distribution for houses not excluded. Both groups must be expected to have housas with radon concentrations ranging from less than $1 \mathrm{pCl} / 1$ to greater than $10 \mathrm{pC} 1 / 1$. The concentration distribution for the excluded group will alnust certainly have somewhat higher levels than the distribution for permitted houses. But differences of factors of three or so that are obtained by selecting on the basis of present criteria are small compared with the 1000-fold range in indoor concentrations. (On the other hand, requirement of such criterla, wilch make selections on the basis of factors of two or three, is a relatively strong response to the 20-30\% change expected from infiltration reduction.) As discussed below, improved understanding of source magnitude distributions may provide a basis for more appropriate selection criteria.

Fundamencally, three major factors affect the Indoor radon concentration: local source strengths, radon entry effictency, and the ventilation rute. To the extent that these can be considered to be 
Independent of each other, each factor has equal weight in affecting the Indoor concentration, that is to say, a factor of two variation in any of these changes the radon concentration in first order by a factor of two. The 1000-fold varlabilfty actually observed is probably attributable to these factors in roughly the same degree, although there is some indication that the local source strength may vary somewhat more widely than the others, that the next highly varying is the efficiency of transmission into the house, and that the least highly varying is the ventilation rate (this variation is still quite substantial and probably comparable to that for transmission efficlency). Speaking only approxinately, about a ten-fold variability must be expected in each of these factors, merely to include more than $90 \%$ of houses, and the range probably vartes somewhat among the three factors. The excluston criteria, as now formulated, are based, in one way or another, solely on transmission efficiency ( 1 .e., radon entry characteristics).

Turning to each excluded class individually, it is not known how heavily radon entry rates depend on design of the house understructure. It can, however, be safely presumed that, a ventilated crawlspace with (or without) vapor barrlers somewhat reduces ingress of radon from the soll under (or surrounding) the house, as compared with a house with a closed basement. How much reduction is effected ta highly uncertaln, depending not only on the structure itself, but also on such matters as local wind conditions. Horeover, the effectiveness of vapor barriers in inhibiting radon entry in these circumstances is not known. Because of such factors, it is likely that great variabllity occurs in the factor by which radon entry is reduced for permitted houses relative to unrestrlcted entry, 1.e., the case where most of the radon that would come from "free" (uncovered) soll actualiy enters the house. Factors from approximately 1 ( $1 . e$. , almost no reduction) to 10 or more (tenfold reduction) must be e.pected in the full range of possibilities.

Assuming a constant type of pernitted structure (ventilated crawlspace with vapor barriers), the relative reduction (cripared with an excluded alternative structure) will depend on the particulars of the excluded class. Although these relative reduction factors are not actually known el ther experimentaliy or theorecically, it is useful to indicate their probable range, purely as a basis for considering in what clrcumstances slasses might be removed from the exclusion list. At one extreme, that of a closed full basement, the relative reduction factor For a permitted structure may typlcally be in the range of 2 to 4 (but with rare cases in the vicinity of elther 1 or 10 or more). At the other extreme, the ventliated crawispace may offer little more barrier than a welI-constructed concrete slab, particularly a slab systen that incorporates a barrier of some $k 1$ nd. Hence, we might assign a relative reduction factor of 1 to 3 for this kind of system, and sintlarly for a crawlspace that does not meet the vapor-barrier requirements or that is not adequately ventilated. As an example, the difference between a permitted structure and one having a crawlspace without vapor barriers is taken to be a factor of 1 to 3 (a mean of 2), but this may be too great (or eyen too little). loreover, aside from the intrinsic or potential value of any particular measure, its actual effect will depend substantially on construction detalls and other factors that are very poorly defined. 
lone theless, the view that ration reduction factors (relative to free entry) are largely in the range of 1 to 10 , wh most houses between 2 and something less than 10, is consistent with the picture suggested above, that varfability in radon entry contributes about one of the three orders of magaltude range in observed radon concentrations. Viewed from a different perspective, changes from one understructure type to another may cause changes of roughly a factor of 2 or 3 (on the average) in radon entry rate: small compared with the wide range in radon distribution (range of 1000) and large conpared with changes in ventilation rate due to tightenting ( 20 to $30 \%$ ).

Thus, if the full range of radon concentrations is of the order of 1000 , the excluded group of houses will have a range in concentrations of roughly 300 to 500 , as will the permitted class, assuming a factor of two or three difference between the two. Assuming a factor of three would mean, for example, that if the full range were 0.05 to 50 pCi/1, the excluded houses would have 0.15 to $50 \mathrm{pC} 1 / 1$ and the permitted houses would have 0.05 to $17 \mathrm{pC} 1 / 1$. Tightening these two classes by $20 \%$ would yleld ranges of 0.18 to $60 \mathrm{pCI} / 1$ and 0.06 to $20 \mathrm{pC} 1 / 1$, respect 1 vely. The two classes have similar ranges, each with some high levels, and are stimilarly affected by infiltration reduction. (Itowever, the upper end of each range may nüc change as much as indicated, since being at the high end of the range probably fiplies a ventilation rate that is already lower than average and hence not as susceptible to tightening; the lower end way not change much because oî the relatively large influence - at such low levels - of radon in outdoor a1r.)

These nominal ranges and changes are highly confectural and neglect the differences in the excluded classes (noted below). They do, however, 1 llustrate the key point, 1.e., that the range mus $i$ be expected to be very large $1 \mathrm{n}$ both permitted and excluded classes, the main difference being a small relative shift of the two distributions. Further, as discussed at greater length in succeeding sections, the key to reducing the average exposure is to Identify cases or areas with high local sources, and not only to avold measures that rafse concentrations in these areas but to cake steps to reduce them. This would be the equivalent of altering the formulation of the exclusion criteria to have a more fundamental basis. Such alteration can be accomplished only on the basis of Improved Information, specifically the Identification of the portion of the housing stock with large source magnitudes. At the same time, presently excluded homes with low source magnitudes could be offered infiltration-reducing measures.

We turn again to the various classes excluded on the basis of differences in house understructures: those witn basements, nonquallfying crawlspaces (partial basement/slab, unventilated, no vapor birriers), or concrete slabs. A typical distinction between excluded and permltced concentration ranges and changes has been given above. Depending on the excluded class(es) in question, the distinction will be slightly greater or less, but not qualitatively different. The parameter of ultimate interest is, of course, exposure to radon daughters, a schematic repreventation of which is given in figure 4-1. Because the distributional argument just made for concentrations extends equally well to exposures, it can be expected that, for each of the excluded 


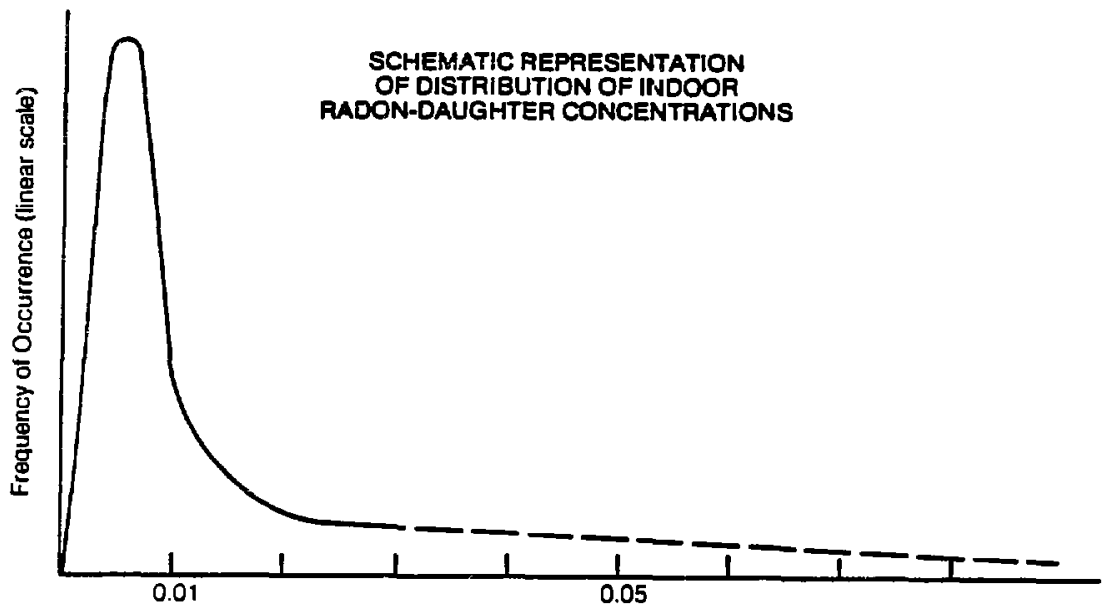

Indoor Daughter Concentration (Working Level)

Fiqure 4-1. Schematic representation of the distribution of indoor radon-daughter concentrations. Most of the population is in the peak at low concentrations, and hence exposure rates. However, a significant number experience much high exposure rates, so that they suffer unusually large individual risks and, moreover, so that a substantial oortion of the total exposure (and hence aggregate risk) occurs among a small number of the population. See also figure 4-2.

Figure 4-2 (following page). Survey of radon-222 concentrations and implications for associated risk of lung cancer. The upper part of the figure shows the number of houses found to have radon concentrations in four ranges: 0 to 1,1 to 5,5 to 10 , and 10 to $30 \mathrm{pCi} / 1$. (These results are taken from: A. V. Nero et al., "Radon Concentrations and Infiltration Rates Measured in Conventional and Energy-Efficient Houses," Lawrence Berkeley Laboratory report LBL-13415, Seotember 1981, submitted to Health Physics.) The lower part of the figure gives estimate of the corresponding U.S. lung cancer rates attributable to exposure to radon daughters indoors, assuming the housing sampled is typical of the U.S. housing stock, that annual-average radon concentrations are half those given in the upper part of the figure, and that the equilibrium factor is 0.5 . Note that half of the aggregate risk can be attributed to the $15 \%$ of the houses having concentrations in the two upper ranges. Even higher concentrations than those given here have been found in the BPA area. (Because radon was measured with all windows and doors closed, the resulting concentrations cannot be taken as annual-averages in the houses monitored in this survey. Moreover, this sample was accumulated in a manner that probably gives too great a representation to hous $\in$ S that are "tighter" than average or that are located in "high radon" areas.) 

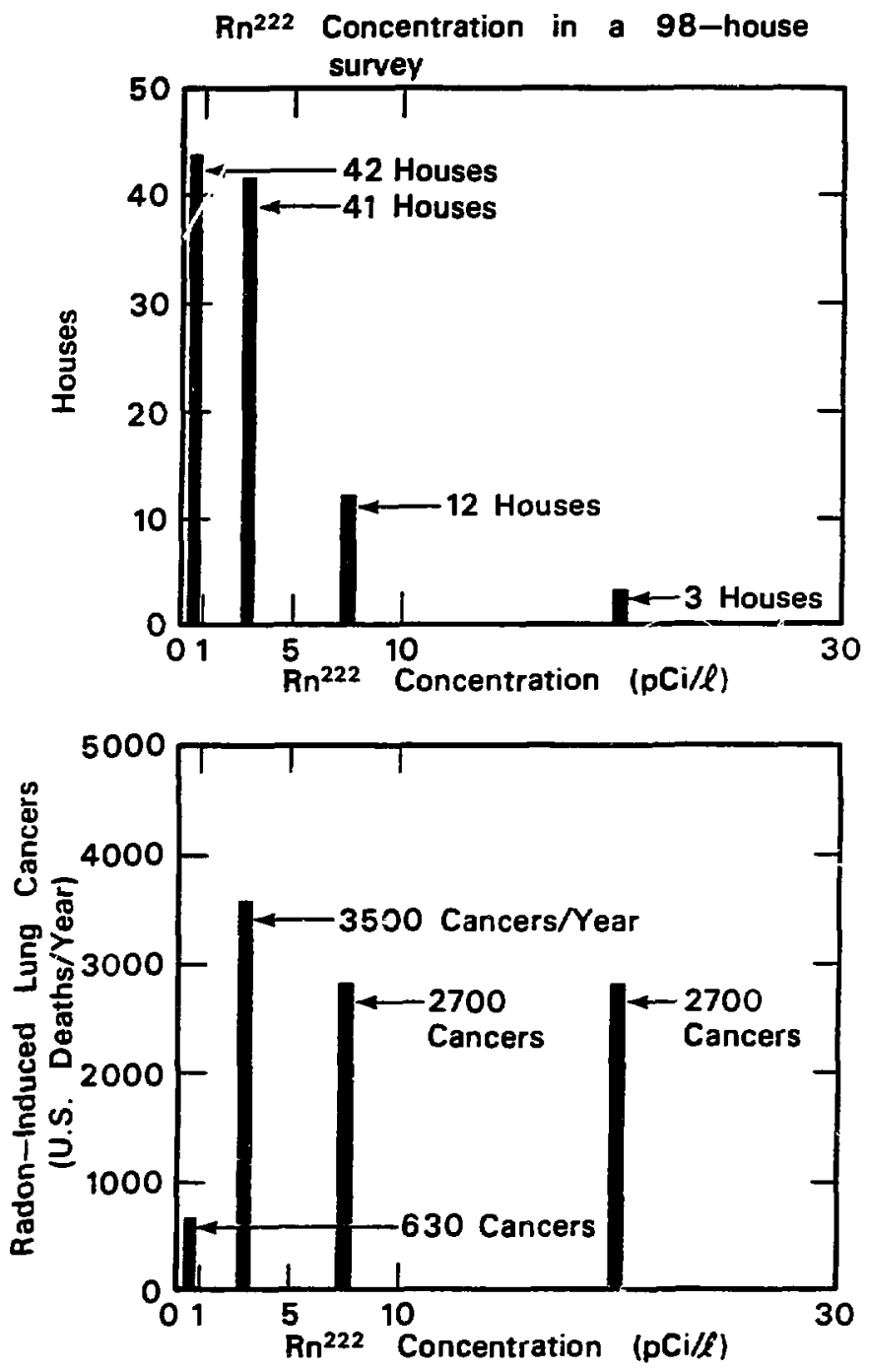

Figure 4-2 (caption on previous page). 
classes, the bulk of the population occurs in the peak at low exposure rates.

The foregolng discussion of radon has dealt only with the influence of understructure and other factors on indoor concentrations of radon entering from surrounding soil and rock. Fxcept for the issue of the efficlency of radon entry, much of this discussion is pertinent to the two other radon exclusion classes, which are based on water source and buflding materlais.

Based on experience in the United States, household water is the second most important means by which radon enters houses. As Indicated by the exclusion as formulated, this occurs primarily with water from private wells. In areas with unusually high radium concentrations, significant amounts of radon way thereby enter houses. For typical water usage, a radon concentration of 10,000 pCl per 11 ter of water sustains an alrborne radon concentration on the order of $1 \mathrm{pC} 1 / 1$. Concentrations of this size or greater have been found in several parts of the country. Although detalled evidence is not yet avallable, it can be expected that high concentrations in household water w1ll correlate roughly with areas with high emanation of radon from solls and entry of such radon into houses. A possible exception occurs when ground water travels long di:tances, but the impact of such transfer tends to be mitigatea by jecay of radon during transit and by mixing with local waters.

Because radon content of household water from wells can vary from on the order of $10 \mathrm{pCl} / 1$ to in excess of $100,000 \mathrm{pC} 1 / 1$, the contribution to alrborne radon concentrations can vary from about 0.001 pCi/1 to 10 $\mathrm{pC} 1 / 1$ or more. As a rule of thumb, water may therefore contribute, on the average, about an order of magnitude less radon to indoor air than radon from beneath the structure, although there are known to be exceptions. Furtheimore, the relatively high contributions should ordinarily occur in the areas where, because of geologic factors, relatively large amounts of radon are also avallable for direct entry via house understructures or for Indirect entry via building materlals (discussed just below). As for the effect of 1 ifiltration reduction, a range of precisely 0.001-10 pC1/1 (contribution from water) would be altered, by a $20 \%$ infiltration reduction, to a range of $0.0012-12 \mathrm{pC} 1 / 1$.

Finally, bullding materials can constitute - in unusual cases - a signiflcant source of radon. For materlals derived locally and used in single-family dwellings, the contribution is usually small. For example, a typical full concrete slab in a single-story residence can ordinarily be expected to contribute less than $0.1 \mathrm{pCi} / 1$ to the indoor a1r, assuming no sealant. Smaller amounts of interlor masonry with similar emanation rates would contribute correspondingly less, so that - ordinarily - radon from Interior concrete or masonry can be expected to be substantially less than that from the ground under and around the house. Looking at this in a simple way, there is much more radon-emanating material around than in the house. Characterizing areas with respect to soll as a radon oource will also ald in characterlzing local bullding materials. The principal exception is waterials derived from Industrial processes that concentrate radiun or that use non-local materials (or mined materials whose orfgin correlates geochemically with that of 
radium). Specifis attention should be given to such special cases (as led to current studies being undertaken in Butte), thereby avolding the tendency to ascribe such difficultteg to ordinary bilding materials.

\section{B. Wood Stoves and Unvented Combustion Appliances}

of the two exclustong in this category, that with wood stoves is the larger, constituting as much as half of BPA-served, electrically heated homes. It should be noted that houses with fireplaces are not excluded In appendix E. Invented combustion appliancea (whether gas stoves or heaters) are present in only a few percent of the BPA houses in question.

The contribution of wood stoves to contamtnants in indoor air is not well characterlzed and dependa greatly on the specific system in question and on the manner in which it is operated. Even the few data avallable (see section 2) ouggest that average and peak concentrations for spectfic pollutants can vary frow a small fraction of to noticeably greater than standards applicable to outdoor exposures to these pollutants.

Based on the limited indoor wood stove data in the lfterature, it might be expected that average total suspended particulate (mSP) levels In homes with wood stoves during "heavy" use could range from essentially outdoor levels to over $300 \mathrm{\mu g} / \mathrm{m}^{3}$. Comparable resplrable suspended particulates (RSP) concentrations might have a slighrly reduced but similar range.

Polycyclic organic matter (POH) -- also called PAll or PHA -- levels can range from 0.2 to $4 \%$ of the particulate levels reaulting from wood stove use. Benzo-a-pyrene (Bap) -- part of the Poll class of pollutants - levela would obviously be less.

Indoor measurements of gageous pollutant levels from wood appliances are limited. Whole house peak to levels have ranged from less than 3 to $225 \mathrm{ppb}$. And peak $\mathrm{HO}_{2}$ levels have ranged from 3 to $320 \mathrm{ppb}$. In the case of both indoor gaseous and indoor particulate concentrations from bood stove use, the varlation from house to house far exceeds any varlat1on expected from a residential alr-tightenting program.

The significance of enissions is Ifkely to depend, not oniy on pollutant jype and emisston rate, but also on the use factor: the fraction of tine the system ta In operation, or the number of times it is started, stoked, or reloaded. There is evidence that fireplaces can also pollute indoor environments. Low use factors or the untested assuiption that In practice fireplace fluea remove all pollutants are presumably the basis upon which fireplaces were not excluded from inftial partic1pation in the tightening aspects of the program.

Finally, the question of pollutant enission rates over time has not been addresied. Since creosote bullds up in the flue of sny wood o: coal appliance, it must, if not cleaned, eventually reduce the flue efficlency over time and increase the wood stove's potesilal for polluting indoor environments unless the flue is cleaned regularly. This 
might Imply that some advice on regular flue maintenance be given to the homeowners if alr tightening measures are performed.

Use of unvented combustion appliances, such as gas stoves or heaters, can contribute substantial indoor concentrations of oxides of carbon and nitrogen, formaldehyde, and particulates. Avallable data (section 2 and 3) Indicate that concentrations of one pollutant ot another can reach levels above outdoor alr quality standards depending on the clrcumstances. Venting, of course, avolds most such emissions, assuming integrity of the flue system. Even local ventilation - such as a hood operating over a gas stove - is relatively effective in preventing entry of these emissions trito the general 1ndoor space. Assuming no venting, reduction of infiltration rates by 20 or $30 z$ will raise indoor concentrations, whatever they way ve, by a corresponding amount.

\section{Irea-Formaldehyde Insulation and Other Formaldehyde Sources}

Formaldehyde-emitting materials that are used in the house structure or furnishings can contribute oubstantial concentrations of formaldehyde to indoor air. The most notable such source has been urea-formaldehyde foan insulation. Concentrations above $1.0 \mathrm{ppn}$, well above proposed $11 \mathrm{~m}^{-}$ Its and sufficient to cause acute distress in a significant portion of the population, have been found lif firses with such insulation. Although the distribution of concentrations in these houses is not well defined, it is known that, depending on how well the insulation 15 installed, substantially lower concentrations are the norm, reaching the range that might be considered acceptable. However, a significant enough portion of houses with such insulation have concentrations at or even well above proposed guidelines for the general public that it does not appear prudent to reduce ventilation rates, however slightly, in such houses without 1dentifying those homes with elevated formaldehyde concentrations. (This identification could be accomplished by performing a measurement to determine concentrations in the houses in ques(ton.)

It is also known that other sources of formaldehyde can lead to high alrborne concentrations indoors, speciflcally materlals that are used in finishing house interlors (such as plywood, particleboard, carpet adhesives) and in furnishing them (furniture using simllar material). The presence of such materlals are known to lead to alrborne concentrations in the range of 100 to a few hundred $\mathrm{FPb}$ in a significant portion of cases, at least soon after installation. Even use of gas stoves (without use of a ventilation hood) can contribute concentrations in the range of $100 \mathrm{pPb}$ at normal ventilation rates. At very low ventilation rates (such as commonly occur in moblle homes or in unusually tight frame structures), the concentrations can even extend above 1.0 ppm. The latter cases are not directly pertinent to the weacherization program, since ordinary tightening would presumably have negligible effect, but even concentrations in the 100 to few hundred $\mathrm{ppb}$ range have to be considered carefully, considering that some proposed standards place IImits (rather than averages) as low as $100 \mathrm{ppb}$ for the general public. On the other hand, there is reason to think that houses that initially have concentrations in this vicinity will, eventually, have considerably lower concentrations as the source materials outgas and the emission 
rates decline. Thus a ventilation reduction that Initiaily ralses 100 ppt to 125 ppb would, as an exanple, later be responsible for ralsing a $40 \mathrm{ppb}$ concentration to $50 \mathrm{ppb}$. 


\section{CEITERIC COISIDERATIOIS III ALTERIIC THF. EXCLUSIOH LIST}

A. Requirements for Removing Classes from Exclusion List

Removal of a class from the exclusion list entalls one or both of two elements: development of improved information on sources, concentration, or controls; and implementation of strategies to assure that tightening of houses in the class in question will not cause a significant impact on occupants. Formulation of criteria for judging such impacts are alsc 1mportant. Development of Information or mitigating strategles, as well as criteria, can take place elther as part of the weatherization program or as part of other efforts, elther for BPA or otherwise. It 1s useful to consider these possibilities explicitly before proceeding to the thethodology itself.

The first basis on which the exclusion list might be altered is that, based on presently avallable information, certain classes as previously defined may designete factors that are not themselves the origin of potentially significant impacts or that are inappropriate exclusion criteria on other grounds. As an example, it is concelvable that the criterion on Interior masonry might be removed on the prentse that this source in virtually no case contributes the bulk of the radon entering a house, so that any significant impact on radon levels from infiltration reduction would arise primarily from other sources associated with the house. Another example would be removal of the exclusion against gas stoves, provided that an operable ventilation hood was in place. On the other hand, reconsideration could also suggest addition of classes to the exclusion list if reevaluation Indicated a significant enough potential Impact from houging characteristics other than those initially on the exclusion ist. (See section B, below.)

A second basis for removal of classes from the exclusion list is that the weatherization program provide a mechanism for information development end, if needed, mitigation. As an example, indoor monitorIng or detalled source characterization would be a reasonable basis for deciding that certain houses could be tightened without significant Impact or for deciding which houses required mitigation as a condition of tightening. Such mitigation, In some cases, could even occur a sisnificant time after tightening, for those cases where acute effects are not $11 k e l y$ to result and where cumulative effects could be avolded. A significant portion of the gection on wethodology will entall development of information and use of mitigation measures as part of the weatherization program.

The third basis for removal from the exclusion list is simflar to the last, except that the development of information or mitigating strategles need not be part of the weatherization progran per se. As above, this development could occur concurrently with or after weatherization 1tself. There are several important possibllities of this type:

1. Parallel or subsequent characterization of Indoor air quality with respect to housing characteristics in the BPA area may better distinguish those classes or subclasses of houses that Iequire oitigation in connection with tightening measures. For example, the 
regional indoor alr quality field survey described by GEOLET (and proposed in a different form by LBL) could give explicit information on the dependence of Indoor pollutant concentrations on housing classes, Information that would be useful in deciding which houses on the exclusion list might be removed and which require more detalled Investigation. As a simllar, perhaps more far-reaching possibility, successful geographic characterization of radon sources could provide a firm basis for permitting tightening of most of the houses now excluded on the basis of radon criterla. Such characterization could occur from use of presently avallable data that map radon daughters on the basis of aerial measurements or from performance of new measurements orlented directly toward radon source and entry characteristics; as a practical matter, effective and Inexpensive mapping may require a combination of these two approaches.

2. Studies performed for entities other than BPA could provide Information directly relevant to use during or after weatherization. For example, new monitoring techniques might ease the problem of measurement in all or a sample of houses weatherized. Hew information on the effect of aging on formaldehyde emissions could affect micigation strategles. As another example, testing of measures to reduce radon transport cheaply could directly affect the suitability of tightening certain houses (or of living in them regardless of tightening measures).

3. The fact that BPA is developing an envi romental Impact statement on the weatherlzation program could retrospectively alter the basis on which weatherization can occur. It may also mean that houses that are tightened on the premise that mitigation will take place later, If needed, may find the need for mitigation removed on an administrative basis. The prospect of a substantive exemination of benefits and costs associated with the weatherization program conid therefore be an 1mportant element in a methodology for removal of classes from the exclusion Iist. Ho longer would "no significant impact," whether individual or aggregate, be strictly required.

The next section discusses circumstances in which it might be desirable to add classes to the exclusion list, an action that might even be required in connection with removing classes. Such a linkage is clearly possible if the radon exclusion criteria are reformulated. For example, ident sfication of areas with unusually high radon sources might then permit tightening of houses elsewhere (low radon sources) regardless of understructure type, but it ulght - at least inftially - also require withholding of tightening measures from any houses (even with "permitted" understructures) In the high-radon areas. On the whole, though, this reorientation of the exclusion criteria would probably lead to a much smaller excluded class. Information required for such alteration of the exclusion list is discussed in the radon part of the next section. 


\section{B. Adding Classes to the Exclusion LIst}

A substantial question to be considered and that will necessarily arise is whether other classes ought to be added, on one basis or another. Before proceeding to alterations that are nominally additions to the exclusion list itself, we consider another possibility that is effectively such as addition, but that is actually a redesignation of what measures result in tightening of the building envelop.

As noted in section 1, weatherization measures are divided at this time Into two classes: those that do not cause infiltration reduction and those that do. However, two of the measures that are now regarded as not significantly affecting infiltration rates actually could affect infiltration or ventilation rates. The first is "vapor barriers", which may include those Introduced along with insulation. These barriers, although not causing gross infiltration reduction (such as might be assoclated with continuous plastic sheeting incorporated in the bullding envelope), can cause a modest reduction in rates. Secondly, the sealing of afr ducts can cause a substantial reduction in ventilation rateo, because - as of ten Installed - ducts are leaky enough that, when the HVAC systen in operating, ventilation rates are raised by forcing air through the leaks, at least when the ducts pass through unconditioned space (such as the crawlspace or attle). Th1s leakage can be substantial enough that sealing ducts can have as great an effect on ventilation rates as all the nominally tightening measures taken together. $A$ posstble basis for ereating this measure as was done in the Environmental Assessment is to take the polnt of view that the ducted heating system is not intended to provide ventilation via leaks, so that operating a leaky system results in a "looser" house than is intended or reasonable.

Even more significant, it appears, is the possibility of altering or adding to the classes already on the exclusion list Itself. Such possible changes apply to every exclusion type that we have considered: radon, combustion products, and formaldehyde.

Radon

As noted In the discussion of section 4 , a more fundamental exclusion class for radon would be oriented around the extent to which local radium-bearing source actually enit radon. Identification of situations with large radon sources can be undertaken using a nuinber of different approaches. It !s possible, In fact, that tentative high-radon geographic areas could be chosen merely by analysis of the aerfal urantumsurvey data (IITF: Iational Uranium Resource Evaliation) accumulated over the last decade; this survey actually measures radon daughters, a signiflcant Indicator of radon sources. Undoubtedly, the results of such analysis would have to be verifled by local measurements, but the effort required for such an approach could be small compared with an effort that did not use this information. Some of the local measurements that would be required are of the same kind as has been suggested to BPA by LBL researchers. (Th1s question is treated at greater length In eection 6.) An alternative approach is to design a geographic characterization progran that is dependent on other prograns (such as the regional IA? fleld program) or that is independent (such as the reconnaissance type of survey sugge日ted by CEOIE: $)$. Regardless of the basis, 
If radon sources or concentrations can be localized geographically, houses could be excluded on this basis, rather than using the criteria on the present exclusion 11st.

It Is Important to note that such a reorientation of exclusion criteria could result in the actual addition to the exclusion ilst of houses that are not presently on 1 t. This is not a necessary outcome, but it is possible if - as suggested in section 4 - relatively high radon concentrations can occur Independently of the present excluston criteria. An alternative outcone, of course, is that only in geographic areas found to have high radon sources would the present exclusions be retalned.

An alternative to source characterization as a means of finding high rador areas $1 \mathrm{~s}$ simply to measure indoor concentrations as part of a widespread program, such as weatherization. Such measurements lone could actually form a basis, not only for declsions on particular houses, but for classification of high-radon areas. Such a measurement program could be a relatively inexpensive means of classifying areas, particularly if used together with successful classification based on the IIUPE data (since that, too, would be relatively inexpensive).

Combustion Products

The exampleg glven here would be additional exclusions based on other combustion sources than now set forth in the exclusion criterta. He understand that the explicit purpose of this document is not to suggest such additions, but set out considerations pertinent to fireplaces and smoking for consistency and completeness.

Presently one of the largest excluded classes is that containing wood stoves. However, houses with fireplaces might also be excluded on the same basis. In many circumstances, fireplaces can contribute significantly to indoor concentrations of combustion products, fncluding not only oxides of carbon and nitrogen, but also organfcs, often on alrborne particulates. Indoor emissions from fireplaces may even exceed those from wood stoves.

One bagis for permitting tightening of houses with fireplaces is that they may not be operated a substantial fraction of the time, so that their average effect on indoor alr quality is not great. Ilowever, it does not appear that the Environmental Assessment explicitly considered fireplaces as potential sources of combustion products indoors.

The chofce of whether or not to exclude houses with fireplaces must be made considering in some detall the various emissions that arise from their use, as well as the use patterns that are assoclated with fireplaces. A complicating 18sue is the extent to which infiltration reduction affects fireplace operation by reducing the manner in which the chimney draws (or by reducing the need for other heat sources) and, on the other hand, the extent to whicb operation increases the ventilation rate in the house. 
A second combustion source that might have been considered for the the exclusion list is tobacco smokers. Smoking produces significant average concentrations and umusually high peak concentrations of a number of poliutants. Fortunately, the peak concentrations are not ordinarily affected as strongly by reductions in infiltration rate, because the peak concentration bullds up too quickly to be affected by the exchange of indoor and outdoor a1r. Th1s, however, is not the case for average concentrations or the rate at which peak concentrations decrease, both of which are strongly affected by the ventilation rate.

Snoking 1s, of course, not a house characteristic and, considering the general awareness of the adverse health effects of swoking, Indicates explicitly a voluntary acceptance of tncreased risk. Moreover, exposure to smoke by children usually occurs as a result of someone else's cholce, 1.e., their parents. Horeover, even though it can be argued that the increase in this "voluntary" risk (due to infiltration reduction) is modest, subsequent omers of the house would have had no cholce in, and may not be aware of, the tightening. This question is complicated even more by the issue of individual versus aggregate risk, because - even with tightening of the kind provided in the weatherization progran - the house will very likely have an infiltration rate within the nornal range. Ilence a subsequent owner can as easily have bought an "unweatherlzed" house with sintlar alr exchange characteristics. On the other hand, the aggregate effect of the program will have been to increase the average (as opposed to the individual) risk sightly by shifting the housing distribution in the direction of lower infiltration rates. The questions of individual versus average risk and of occupant responsibility are discussed in the next subsection.

Formaldehyde

As suggested in section 4, even houses other than those with ureaformaldehyde insulation can have significant alrborne concentrations of farmaldehyde. The most common source (aside from unvented combustion appliances) is use of plywood, particleboard, or certain carpet adhesives, as well as the introduction of new furniture. On the presumption that it is the bullding materials that constitute the most significant source, an exclusion could be based in principle on bullding age or on inspection (although it can be difficult to identify potential formaldehyde sources visually). An alternative to a source-oriented exclusion is to perform an integrated formaldehyde measurement, much as Is also possible for radon. These two distinct approaches could be combined, e.g., by performing measurenents in relatively new structures only.

\section{Plsk, Standards, and Responsibility}

In examining how to avold significant impacts on the population, several broad questlons arise in the area of how such cholces are made. The first obvious difflculty in this area is that speciflc criteria do not exist for determination of when Indoor pollutant levels are exicssive. In fact, even if specific standards existed for the generai population in their homes, it is not clear that this in 1 tself would remove the onus of responsibility for health effects among that portion of the 
population that is more sensitive than average to particular pollutants and hence is not adequately protected by any particular mumerical gulde1Ine. Ir such situations, it often is necessary, as a practical matter, that the burden shift directly to the Individual to make choices necessary to protect his or her own health. loreover, even in cases where numerical guidelines exist, the response to exposure to the pollutant in question cannot be assumed to involve a threshold; in many cases, the assoclated risk simply decreases with dose, so that at some level the Individual risk is deemed acceptable. flowever, this fudgment must be nade in the context of a particular option and, in any case, does not remove the responsibility for considering the aggregate risk that may acirue as the result of a progran involving many people.

It Is useful to consider the question of Individual versus aggregate risk in another concext, 1.e., In deciding when a program has "no signiflcant impact". The existence of any applicable concentration limit (whether a guideline or a standard with regulatory force) for a particular pollutant gives some indication of the extent to which individuals ought to be protected, assuming that the limit was developed for protection of Individuals and not to control average exposures. Unfortunately, this distinction is of ten not drawn: occupational standards are usually designed for protection of indtulduals from excessive risk, but standards for the general population often make no distinction between individual Ifmics and average IInfts, an obvious exception belng radiation standards. Nonetheless, for cases (such as radiation doses) where the riak can be taken to be proportional to the dose, a simple approach is to take measures to assure that individuals are not caused excessive risk and, at the same time, to assure that the aggregate (or average) risk does not Increase unduly. To assure "no significant Impact", It may be necessary to assure that the average risk does not Increase at all (while, of course, avolding excessive individual risk). This perspective will be important in fashioning an approach to altering the exclusion criteria based on rador exposures. Whether $1 \mathrm{t}$ can be extended to other pollutants is not clear.

A final question, related to much of the discussion in section 5 , is the extent to which, in ambiguous cases, the occupants may be relied on to make their own judgments of what is acceptable, as well as to take actions that will limit their own exposures, to the degree they wish. Several examples are obvious:

1. Use of a ventilation hood is known to have a substantial effect In reducing the spread of gas stove emissions into the general living space (and even the kitchen). The exclusion against gas stoves could, in principle, be removed on this basta.

2. Smoking is a significant indoor pollutant but has a clearly voluntary component. Nloreover, subsequent house occupants may have different smokling habits than those when infiltration reduction measures are implemented. The fact that households with swokers are not on the exclusion 11 st can only be based on the "voluntary" nature of this practice. 
3. The question of how other combustion sources contribute to indoor pollutant levels also depends highly on practices of the occupants. Gertainly emissions from wood stoves can depend on stoking procedures. The same is also true of fireplaces. Moreover, in etcher of these cases, the amount of contaminants actually produced depends on how of ten the stove or fireplace is employed, clearly a mitter of choice (although the use factor might be lower and the variation higher for fireplaces than for wood stoves). 
This section outlines the essential elements that might be associated with alteration of the $11 \mathrm{st}$ of housing classes excluded fron the infiltration-reducing elements of the weatherization program. The outI1ne emphasizes grounds for renoval or reduction of the presently excluded classes. In a number of cases, we also indicate, consistent wth the discussion of the last section, possible additions or expanslons of housing classes on the 11 st, sometimes as a part of reformulations to reduce the total number of excluded houses.

The three essential aspects of alterations of the 11st are: development of better Information characterizing sources or concentrations; adoption of criterla for judgement of acceptability; and - where appropriate - selection of mitigating measures. Few of these elements are now avallable for most of the classes now, or potentially, excluded.

In spite of this, it 13 important to realize that tentative cholces and strateglc plans can be adopted sooner than full development of Information, criteria, or mitigating measures, provided that the plan provides an adequate course of action to be associated with the results of such development. As a result, the question of sequence and timing is an Important component in the delineation of a methodology for alteration of the exclusion list.

\section{A. Radon Exclusions}

The potential for reorientation of the radon exclusions is treated substantially in gectlons 4 and 5 . This section indicates the spectfic actions that might be essociated with such alteration of the radon exclusion criteria.

Information Development

Two related approaches a re possible in renoving houses or housing classes from the radon portion of the excluston 1ist. One is based on acquiring information on Individual houses, the other on houses by group or area. The measurements required may be orlented toward indoor monftoring or source monttoring.

Indoor monttoring - Individual houses can be monltored using commercially-avallable integrating radon detectors. These should be used as basis for deciding whether to tighten or, if tightening has already been performed, whether to introduce mitigating measures. As such monftoring proceeds, the accumulated data could also be used for characterizing areas in respect to high-radon potential, to the extent such characterization is possible. Use of Indoor monitoring for such purposes can therefore connect with area studies, below.

Source montcoring - in princlple, Individual sites could be monitored to determine source strengths, particularly for radon from soil. This approach would be more expenslve than Indoor monttoring as a basis for decisions on Individual houses, even assuming adequate merhods are avallable. On the other hand, used less extensively, 1.e., at only a 
selection of sites, such data could constitute a basis for geographic characterization of radon source strengths, particularly if used together with other data, as discussed below. Finally, some effort could be made to sample water and bullding materials to assess the potential importance of these sources in the BPA area.

Geofraphic characterization - areas could begin to be classifled as far as radon sources or Indoor concentrations, elther on the basis of accumulated measurements that are otherwise intended to characterize individual houses or on the basis of area studies specifically designed for this purpose. Furthermore, the Individual indoor or source measurements can be used to support and validate classifications based on the area studies. These studies could be actual monitoring prograns (such as the regional IAC ffeld program or systamatic geologic studfes) or analyses of presently avaflable, but unutilized, geologic or radtometric data. Of particular importance in the last category are the data resulting from the llational Uranium Resource Evaluation (IIUPE), which performed aerial surveys of the United States, using sodium fodide derectors to measure gamma rays from various radionuclides, including radon daughters. Only a minimal effort would be required to examine the success with which the HURE data can be used for geographic characterization of radon source strengths. If success appears likely, such classification could proceed rapldly, supported by modest validation efforts using data from other programs $(e . g \cdot$, the regional IAn study and data accumulated in the course of the weatherization program) and a small amount of newly-accumulated source data. An alternative type of area study is the search and reconnatssance approach proposed by GEOIET. However, 1 t appears that use of the IIURE data would be much more efficient in terms of $t$ ime and money.

To summarize information development, a useful near-term approach will be to begin indoor monicoring of excluded houses, while devoting modest efforts to soll source characterization and a minor (but rapid) corresponding effort to examination of the suitability of the IUURE data for geographic characterization. A sampling of water and building materials could also be made to see whether these excluded classes can be removed on this basis, considering that geographle characterization should also cover these classes in large part. (Note: in any area in which indoor monitoring of excluded houses is performed, it would also be extremely valuable to monftor a smaller number of permitted houses in order to determine directly the effect of differences in understructure.)

As noted, the timing of removal from the exclusion lise can vary greatly, as can development of information, criceria, or mitigation. There are two key choices in respect to information: first whether individual monitoring takes place before or after tightening (and at what time mitigation takes place) and, secondly, how this helps in the development of geographic classifications. Although other possibilities exist, the most advantageous approach appears to be to begin tightening and monitoring in parallel, with a comoltment to retrospective of tigation as necessary, and to begin accumulation of a data base both from these regults and from modest source and area studies, leading to 
geographic classification. The monitoring techniques necessary for this approach are, for the most part, avallable, the one exception being the need for testing of some source monitoring techniques. A more critical need is the adoption of criterla for judgement of when tightening and/or mitigation is appropriate.

\section{Criteria}

The principal objective of the exclusion criteria is to assure that "no significant impact" arises from tightening. Removal of the excluslons depend on assurance of in significant lmpact, to Individuals or to the affected group In aggregate. Criteria developed for this assurance could be modified subsequently on the bais is of subsequent environmental Impact assessment, particularly the expected Environmental Impact Statement.

Ilo significant individual impact - in a number of special circumstances In the UnIted States and Canada, suggested limtts on Individual houses have been placed in the vicinity of $0.015-0.02 \mathrm{WL}$, the equivalent of 2 to $10 \mathrm{pCl} / 1$, depending on the equilibriva tactor, or 3-4 pCi/1, assuming a factor of 0.5 . These guldelines were developed for communities in mining areas, presumably subject to higher than average concentrations, but 1 is now known that apparently ordinary areas throughout the United States can have signiflcant numbers of houses with concentrations exceeding 3 or $4 \mathrm{pC} 1 / 1$. Horeover, these guidelines were usually developed without making a distinction between individual and average concentration guidelines. As suggested above, a more carefully considered approach should make this distinction. It is therefore suggested that average concentrations in "ordinary" areas be expected to be maintalned well below 3-4 pC1/1 (see below) but that some portion of houses be expected to be above this 11mit. It is thought that several to ten percent or more of U.S. houses exceed th1s $11 \mathrm{mI}$, so that a range of 5 to $10 \%$ exceeding $3 \mathrm{pCl} / 1$ might be taken to be acceptable. On the other hand, substantially fewer should be expected to exceed, say, 6 $\mathrm{pCl} / \mathrm{l}$ and - at some point - the level is so high, say in the vicinity of $10 \mathrm{pC1} / 1$, that mitigation would automatically be recommended, Independently of the issue of tightening.

Criterla for acceptability of individual risk therefore depend an the program sequence. If a measurement is performed before tightening, houses not exceeding 3-4 pC1/1 could be candidates for tightening, in the expectation that most would remain below and only the few in the immediate vicinity of $3 \mathrm{pC} 1 / 1$ would exceed this level, but they would still be less than 5-6 pCi/1. If measurements are performed after infiltration reduction, then the result might be deemed acceptable if no more than $10 \%$ exceed $3 \mathrm{pCl} / 1$ and up to about 1.3 exceed $6 \mathrm{pC} 1 / 1$. In either case, remedial action might be offered for cases exceeding 10 $\mathrm{pC} 1 / 1$, whether or not they have been tightened (thereby helping to assure no aggregate impact, discussed below).

It should be noted that these criteria (and those following) are stated in terms of radon concentration ( $\mathrm{pC} / 1 / 1)$ because such measurements can be performed more rellably than radon daughter measurements. The specific numerical guldelines stated are consistent both with past 
practice in special cases and with current kncwledge of the distribution of radon concentrations in the United States. They are Intended to apply to the "Ilving space" of a house. In sone cases, this designation may be ambiguous, particularly in houses with finished basements, where radon concentratione are likely to be higher than elsewhere in the house. (In ouch cases, 1t way be approprlate to average values in the basenent and upsta1rs, with a welghting factor based on area.)

IIo significant aggregate 1mpact - that average exposures do not increase as a resule of tightening can be assured by performing mitigation in a sufficient number of houses with high concentrations to of $\mathrm{fset}$ the small Increases anticipated in the larger number of houses with low concentrat lons. The mitigating measures can be introduced after tightening or along with $1 \mathrm{t}$. One advantage to retrospective mftigation is that sufficient data can accumulate, either in a particular area or in the entire BPA region, to form a basis for understanding what average levels are and at what level mitigation should begin. It is suggested that at some level (such as $10 \mathrm{pCI} / 1$ ) further Investigation (such as an integrating radon-daughter measurement) should be advised in any case, with the prospect that mitigation meas::"es would always be recommended If average daughter concentrations exceed snme corresponding level (say 0.05 WL). Depending on the actual distribution found, mitigation could occur at even lower levels, but probably not lower $1 \mathrm{n}$ any case than 3 $\mathrm{pC1} / 1$. The objective of mitigation at these relatively low levels would be to avold increases in average concentrations, and - for areas with low concentrations - It is possible that an environmental impact statement could serve as a basis for removing a requirement for mitigation at very low levels. On the other hand, as a tradeoff for using this dual (Individual-average) approach, care should be taken that in no substantial group averages a re ralsed above an acceptable average level, sáy 1-2 $\mathrm{pC} 1 / 1$. Since data are most conveniently accumulated by a rea within the BPA region, some areas my be found that already exceed such an ave rage concentration; in such a case, tightening measures would presumably not proceed (and, as indicated above, remedial action would be taken in houses with excessive concentrations).

Finvironmental impact statement - as just noted, for areas with relatively low radon concentrations, the environmental impact statement beling prepared by BPA may serve as adequate grounds for removing the combitment to no increase in average concentrations, provided that this increase is small enough to be acceptable, considerting other costs and benefits of tightening.

Melgation

A number of techniques discussed in section 3 can be used for controlling radon concentrations in houses in which mitigation is advised. These techniques fall into the three broad control categories: source control, ventilation, and air cleaning.

Source control - controlling radon from under the house is most easily accomplished when a full crawlspace exists, In which case provialon of adequate ventilation (including, in extreme cases, forced 
ventilation) and/or installation of vapor barriers may substantially reduce entry of radon into the house itaelf. These techniques nay be supplemented by other measures, including Instaliation of vent pipes. (These techniques need systematic testing, both in a controllable test structure and in actual houses.) For houses bullt on slabs or with basements, source control depends on addition of sealants or barriers. Since entry probably occurs primarily via cracks and other openings, sealants can be most effective in principle, but identification of entry points is required. This might be accomplished using a radon "sniffer," but this technique needs to be developed further. Itoreover, the effectiveness of sealants needs to be tested. Finally, radon in household water may be controlled by aeration or storage before entry into the house. Systematic testing of source identification and reduction techniques has not occurred. Two proulsing avemes for examination of these techniques are in conjunction with the radon entry and source monitoring studies being performed by LBL and in conjunction with possible remedial actions for high-radon houses in Butte, llontana (identified by EPA/TUD efforts).

Vent1lation - use of mechanical ventilators with alr-to-air heat exchangerg (AAlX) is one means of providing energy-effictent ventilation. For radon control, these devices can be deployed in a number of different ways, Including Installation not only as part of a duct system or in room walls (now being tegted at LBL), but also in basements. In this last configuration, the AAlX removes much of the radon before $1 t$ can enter the rest of the house, and has the added advantage that basements are often more open than main floors, thereby increasing the effectiveness with which the entire space is ventilated.

A1r cleaning - radon-daughter exposures may be subject to adequate control by filtration or other active systems that remove particulatas from the air. Daughters may also be removed, to some degree, merely by circulation of alr within the house. Detalled study of daughter removal mechanisms and the effectiveness of alr cleaning devices is being undertaken by a number of laboratories, particularly LBL and some European laboratorles.

The radon control techniques that are most promising and best understood are those besed on source control and on a1r-to-air heat exchangers (In varlous configurations). Hlowever, each of these techniques requires furthar testing to elucidate the manner in which they should be applied in varlous sttuations. 
B. Wood Stoves and Unvented Combustion Appliances

Wood stoves and unvented combugtion appliances can have adverse impacts on Indoor alr pollution levels. Unvented combustion appliances will not be dealt with in this section since, in general, the lise of such appliances causes elevated $\mathrm{HO}_{2}$ levels, exceeding long-term outdoor standards and, in some cases, short-term standards. The only major exception would be a gas range where a range hood was employed, although BPA could not Insure that the range hood was used. In any case, only a small percentage of households in the BPA region have unvented gas appliances.

The two basic options for dealing with the exclusion on wood stoves are (1) to rely on current knowledge and measure several pollutant levels In each home during perlods of "heavy" wood stove use ("heavy" could be occupant defined on an Individual basis or could be defined by criteria that, still, depend on occupant behavior) and (2) to conduct further research to better spectfy which pollutants are of concern and to develop control strategies in houses with high pollution levels. The first approach does not provide for mitigation measures since such measures have not been identified. In any case, it does not appear possible, presently, to delineate a cost-effective methodology (Including information, criteria, and mitigation measures) that is appropriate to removal of any portion of this class from the exclusion list. Iluch of the same dificulties and Information needs apply to houses with fireplaces.

In proceeding on the basis of present knowledge, there are two Important measurable parameters $1 r$ issessing the Impact of wood stoves on Indoor air quality: the Indoor concentrationis of pollutants during heavy wood stove use and the indoorfoutdoor pollution ratios. With these two parameters and the house alr exchange rate; assessment could be made of whether or not the Indoor pollution leveis in a home are too high, as well as the role the wood stove plays in affiecting these levels. With this information, a strategy to assess the fmpact of a particular wood stove on the Indoor alr quality and whether or not to exclude it from the alr tightening program is relatively straightforward in theory.

The basic strategy would be to measure both the Indoor and outdoor levels of key pollutants and the alt exchange rate during a period of heavy wood stove use. An estimate of the contribution of Indoor air pollution from the wood stove can be made by using the measured parameters as input to a simple indoor alr quality model. If 1 t is true that the Indoor pollutant levels are above a prespecifled level (selected to be in the vicinity of the appropriate standard) and that the wood stove contributed to these 1ndoor levels, then no alr tightenting measures would be performed on the house. This would not exclude the house from being Included in air tightening programs if mitigating measures were successfully implemented. This presumes, of course, that the type of measurement performed and the implied exposure corresponds properly to some applicable standard. 
From a practical point of view, several questions arfse, which ind cates how far we are from specifying the required information, criceria, and mitigation:

\section{Which pollutants are Important?}

2. What Indoor concentration should not be exceeded and for what period?

3. What is the most econonical method to measure the pollutants of concern?

4. What control strategies can be employed to keep the wood stove pollutants from entering the living space?

In answering the first question, data from outdoor studies can be exploited. In gereral, wood stoves emlt a different mix of pollutants at different combustion temperatures and different levels of excess oxygen. At low combustion temperatures (fuel combustion rates below approximately $3 \mathrm{~kg} / \mathrm{hr}$ ), CO, total particulate, hydrocarbon, and POlt enissions all increase dramatically. POl entssions drop at temperatures below $500{ }^{\circ} \mathrm{C}$ while $\mathrm{HO}_{\mathrm{x}}$ enlssions increase with increased temperature. The ratio of $\mathrm{CO}$ to particulate emissions from wood stoves varies from 1 to 200. This Implies that at an RSP concentraction of $50 \mathrm{\mu g} / \mathrm{m}^{3}$ the corresponding $C O$ concentration would range from 0.04 to $9 \mathrm{ppm}$. (RSP concentrations are used since combustion aerosols are typically in the respirable range.) The POl/particulate emission mass ratios vary from apprpximately 0.002 to 0.04 . Thus an indoor RSP concentration of 50 $\mu g / m_{3}$ would correspond to POH concentrations ranging from 0.1 to 2 $\mu g / m^{3}$. $110 /$ particulate entasion mass ratios vary from about 0.01 to 4 , Implying $11 \mathrm{H}_{\mathrm{x}}$ concentratifons between 0.2 and $100 \mathrm{ppb}$ as $\mathrm{HO}_{2}$ when RSP concentrations are $50 \mu \mathrm{g} / \mathrm{m}^{3}$. Part 1culate (and RSP) emissions vary over two orders of magnitude -- from approxinately $0.5 \mathrm{~g} / \mathrm{kg}$ to over $50 \mathrm{~g} / \mathrm{kg}$.

The previous "order of magnitude" analysis shows that, in some cases, long-term outdoor stapdards for $\mathrm{CO}, \mathrm{NO}_{2}$, and suspended particles $--9 \mathrm{ppm}, 50 \mathrm{ppb}$, and $75 \mu \mathrm{g} / \mathrm{m}^{3}$, respect 1 vely - ' can probably be exceeded by each pollutant, Independently of whether the other pollutants also exceed standards. POH considerations complicate che issue substanclally.

Because of the potential carcinogenfcity of POH, GFORTT, In a recent report to BPA, suggested a level of concern for POll (or PAll) of 0.3 $\mathrm{ng} / \mathrm{m}^{3}$, well below levels that would be expected indoors. GFOlET set 1 ts proposed level of concern merely by chosing the minimum detectable leve1. The 1mplication of adopting this level would therefore be that, if any particulate sample from a house contained any measurable amount of POI, the house could not particlpate in BPA's house tightening program. Based on the ratios given aboye, if a house had a wood-stove generategd particulate level of $0.5 \mu \mathrm{g} / \mathrm{m}$, a POH level from 1.0 to 20.0 $\mathrm{ng} / \mathrm{m}^{3}$ would be expected, well above GEOLFT's proposed level of concern. It does not appear possible (if only because of stoking) for a. house where a wood stove is used to have wood-stove generated partiaulace leve1 less than $1 \mathrm{\mu g} / \mathrm{m}^{3}$. Yeasured values range fros approximately 30 co 
$140 \mu \mathrm{g} / \mathrm{m}^{3}$. Therefore, if GFola:s's level of concern were used, essenrially no houses that use indoor wood stoves would be eligible for house tightenting measures. Therefore, elther a higher level of concern must be used or houses with wood stoves will remaln untightened. Since no current standards apply to POH, the remainder of this discussion will Ignore POH. On the other hand, If a specific POH standard is developed, Polt could be treated fust Iike $\mathrm{CO}_{1} \mathrm{IIO}_{2}$, or respirable particles, discussed in this section.

An altered wood-stove exclusion criterion based on current knowledge would consider particulate, $\mathrm{HO}_{2}$, and $\mathrm{CO}$ levels. The critical pollutant leveis, above which no action would be taken, would probably be an average concentration specified to be in the vicinity of long-term outdoor standards. The precise proportion of the vitdoor standard to be taken as an action level depends on estimates of infiltration reduction from air tightening measures, accuracy of instrufientation used, and estinates of variability in pollutant concentrations.

This inttlal approach, depending on current knowledge only, is veasurement intensive and does not include provisions for use of control measures to include houses with wood stoves that enit "too much" pollution. In fact, of the three pollutants of concern -- RSP, $\mathrm{CO}$, and $\mathrm{HO}_{2}$ (or $\mathrm{HO}_{\mathrm{x}}$ ) -- only $\mathrm{HO}_{2}$ (and $\mathrm{HO} \mathrm{O}_{\mathrm{x}}$ ) can be weasured passively and economically. Current measurement techniques for RSP and CO would almost surely prohibit large-scale measurements of these pollutants. In passIng, it is fuportant to realize that many of these same questions apply to fireplaces.

Implementation of a reseazch program on wood stoves and fireplaces is the alternative to an immediate attempt to change the wood stove exclusions; such work vould serve to answer some of the questions raised above and to evaluate the procedures necessary to inplement changes in the exclusion list.

One research component would be to characterize emissions of woodstoves (and fireplaces) more fully. This would involve both laboratory studies and fleld work. The first is already being undertaken for BPA. The second would involve not only integrating measurements, but time-dependent studies characterizing these sources as they are actually used. A fleld research program using real-time alr quality nonitors could:

1. Identify the magnitude and mix of pollutants from wood appliances in actual residences;

2. Identify paths through which the pollutants enter the living space;

3. Identify the effects of burn rates, stove ioadings, excess air, creosote bulld-up, and flue drafts on indoor emissions and the mix of pollutants emitted;

4. Identify and evaluate control strategles such as sealing pollutant leakage paths and increasing flue drafts. 
The basic goals of these atudies would be to reduce the number of pollutants that must be measured in houses with wood stoves and Identify control strategies. One possible outcone of such a study might be that $\mathrm{RSP}, \mathrm{CO}$, and $\mathrm{HO}_{2}$ must all be measured in homes with wood-burning appliances. This very real posstbility should encourage BPA to pursue the development of inexpensive -- optimally passive - monttors for RSP and Co concurrent with an intensive wood stove field study. of course, another option is to ignore houses with wood stoves in any air tightening program.

Ultimately, it is hoped that characterization studies, monitor development, and intigation testing will provide an adequate basis for developing information, criterla, and mitigating strategles appropriate, In the near term, for removal of some classes of houses with woodburning stoves from the exclusion $11 \mathrm{st}$ and, In the long term, for developing a comprehensive approach to tightening residences with woodburning appliances. Thls question is complicated by the Intrinsic difficulties with wood-burning from an environmental point of view: that many substances are produced and that quantitles are relatively large and highly variable, whether in the context of the weatherization program or not. The development of "Indicatox" pollutants and of strategles for assuring integrity of the stove-flue system over operating lifetimes are probably key elements in controlling indoor pollution from wood burning.

\section{Urea-Formaldehyde Insulation and Other Formaldehyde Sources}

The main source of formaldehyde identified in the Fnvironmental Assessment was urea-formaldehyi = foam 1nsulation. It uight be desirable simply to retain this exclusiou. On the other hand, it is probable that a substantial number of homes with urea-formaldehyde Insulation do not have levels of formaldehyde different from other houses of the same age, largely because homes have significant formaldehyde sources other than Insulation. Because, in elther case, the levels may be low enough to be deemed acceptable, by some standard, this section Indicates an approach to modification of the formaldehyde exclusions that is based on use of newly available and inexpensive formaldehyde monitors.

\section{Information}

The principal elements in modification of this exclusion is the determination of which houses have excessive formaldehyde level:s and which houses have "low" formaldehyde levels. This 1nformation can be obtained, on a house-by-house basis, by use of an integrating monitor, such as 1s now being tested by LRL. A decision will have to be made as to deployment and period of integration, but there is no barrier in principla to use of this approach for selection of (presumably the bulk of) houses that have relatively low formaldehyde concentrations. It appears that a one-week Integrated measurement of formaldehyde would be adequate for this "screening" purpose. Ganada has started such a program and is using one-week sampling times. Wide-scale measurements would lead to identification of houses that have very high concentratlons, in which mitigating act lons could then be recommended; this could be used to offset the minor increases expected in houses with low 
conctitrations, simflar to the approach suggested for the radon excluslons.

\section{Criteria}

The choice of a criterion for selection of houses that can be tightened is ambiguous, since no standards have been formulated for general application to the 1ndoor environment. Based on current information, it would be generally accepted that levels above 1 ppm are not acceptable for the general population. In fact standards as low as 100 ppb have been proposed or accepted in a number of cases (and is the standard used by (anada). Accepting a guideline as low as this level for houses with urea-formaldehyds insulation would carry the Implication that other houses with concentrations higher than this level should also not be tightened. Th1s will probably include many newer homes that Include substantial amounts of formaldehyde-emtting bullding materials and furnishings. One difficulty, of course, with any specific criterion 1s that the enission rates from mogt formaldehyde source materials are expected to decrease ag the material ages. Specific criteria could consider this decrease and design the decision (and perhaps informationgathering) framework to take advantage of 1t. For example two standards might be developed, one for new houses where formaldehyde levels are expected to decrease and one for older houses where formaldehyde levels are presumably more stable.

\section{IIItgation}

At this time, it is not feasible to recommend specific wide-scale econonical mitigating measures for formaldehyde, with the possible exception of houses that exceed a high level, e.g., several hundred ppb. For houses with exceptlonal levels, occupants should be advised to take mitigating measures. This could merely entall having higher-than-average levels of natural ventilation or using an air-to-air heat exchanger. llowever, other mitlgating measures such as ammonia fumigation or dehumidification should be studied and implemented if appropriate. To some degree (or for some occupancs), mitigation measures may also be appropriate in houses with intermediate formaldehyde levels (100 to several hundred $\mathrm{ppb}$ ). A component of this progran should determine the extent to which indoor concentracions decrease with time.

Thus, as part of the weatherization propram, consideration should be given to the possibility of 1mplementing a program of measurement to identify which homes with urea-formaldehyde insulation (or homes with othe $r$ fotentially significant formaldehyde sources) actually have high formaldehyde concentrations. It is also approprlate that such measurements be extended to newer homes, which also have a good chance of having significant formaldehyde sources. The monitors required for accomplishing this inexpensively are now beconting avallable.

\section{Other Fxcluded Homes}

The principal categories excluded, in addition to those already discussed, are mobile homes and other homes that do not use frame construction. The set of weatherization measures appropriate to these homes, at 
least for moblle homes, are different from those considered in this report. Deciding how to remove such housing categorles from the excluston list can follow a more careful definition of the applicability of various weatherization measures to these homes.

\section{E. General Hotes}

It Is uireful to mention two general questions that pertain directly to the elenents mentloned above in the methodologies for each exclusion class. One pertains to the sultability of actual monitoring as a basis for fudgment (with the related issue of how monitoring costs compare with the benefits of infiltration reduction); the other $1 \mathrm{~s}$ the extent to which mitigation measures suggested or possible in connection with the various excluded classes need further development and testing.

\section{llonitoring Costs and Mitgation Benefits}

The two pollutants for which Inexpensive integrating monitoring devIces are avallable and for which monttoring could lead directly to removal or reduction of excluded classes are radon and formaldehyde. In each of these cases, the basic monttoring technique costs in the range of $\$ 10$ to $\$ 20$ per sample and the cost of each sample, Including handling and progran management, is likely to be two or three times this number. As a result, for $\$ 30$ to $\$ 60$, each of these two pollutants could be measures. Because this cost is falrly modest, it is not unreasonable to adopt a monitoring-based approach to deciding which houses (or classes af houses? may be renoved from the exclusion list.

Ifaking such a decision, however, depends on the benefits expected to accrue as a result of tightening. The benefit in terms of present value depends on many factors that are beyond the scope of this report. Jlowever, what can be sald simply is that if the expected present value of tightenting exceeds the cost of monitoring $(\mathrm{e.g} ., \$ 50)$ divided by the probability of removal from the exclusion list then 1 t 16 advantageous to perform meastrements in each house in question. The advantage is even greater, of course, if data accumulated in varlous classes serve as a basis for making decisions to remove all or portions of classes.

Estimating the present value of tightening requires knowledge of the cost of tightening, the amount of energy saved as a result, and the value placed on this energy. (Knowledge of discount rates and fuel price escalation are also required.) If, for example, the value of tightening is relatively large, particularly if tightening is accomplished relatively efflctently, and the value of energy saved is taken to be the marginal value, then monltoring coscs would be considered to be unimportant. If, in contrast, tightening is relatively costly and the electrical usage avolded is assigned a relatively low value (e.g., average prices in the BPA area), then the value of tightening is relatively little, perhaps in the same range as the cost of simple monttoring.

Because the cost of performing radon and formaldehyde Integrated measurements is relatively little, the methodology indicated above has Included such measurements as an Integral part of the development. of 
Information needed as grounds for removing houses or classes of houses from the exclusion 11 at.

\section{Further Development of Mitigating Measures}

In connection with the various excluded classes, we have indicated mitigation techniques that might be appropriate to the pollutant of concern. In virtually every case, further testing or development of the techniques is needed to Indicate In more detall how well they perform in varlous circumstances. It is useful to summarize those needs, IndicatIng In addition several that were not treated explicitly above (such as the formaldehyde-mitigating techniques). In some cases, the costeffectivenass of these measures has been examined, but in many the technical effectiveness deserves further 1nvestigation. In most cases a combination of laboratory and field studies is required. In any case, the aggregate cost of mitigation for a specific source category should be less than the aggregate energy savings from house tightening.

1. The ventilation efficlency of mechanical ventilation systems with air-to-air heat exchangers needs to be studied for cases where these devices are installed in windows. These studics are now belng performed at LBL.

2. The suitability of mechanical ventilation of crawlspaces as means to reduce ingress to radon ought to be inves':1gate'1. In addition, the effect of mechanical ventilation (Including, as ont possibility, afr-to-air heat exchangers) on radon entry via basements needs study. As a basis for these investigations, study of the location and mechanism for radon entry into residences should be undertaken.

3. A cholce needs to be rade about depending on range hoods as mitigation for combustion emissions from gas stoves. This may involve depending on occupants to use hoods, but the other possibflity - which would require study - is to Install a mechanism for automatic operation of the hood.

4. Studies of the effect of dehumidification and ammonia fumigation as formaldehyde control techniques are needed.

5. Alr washing techniques for removal of formaldehyde need study and development.

6. The potential use of exhaust a1r heat pumps as indoor pollutant control devices needs investigation.

7. Electrostatic precipitators and other particulate removal devfces need testing. Parallel development of inexpenstve particulate monttoring devices would be extremely useful.

8. The effect of particulate removal devices and a1r movement on radon daughter levels (and states of attachment) needs investigation. 
These control approaches are In various stages of development. llany of then are essential to a sound basis for removal of various classes from the exclusion Ifst, and - In any case - are required to the extent that houses with excessively high pollutant concentrations are Ident 1fied as a result of the weatherization or other programs.

Acknowledgement

This work was supported by the Assistant Secretary for Conservation and Renewable Energy, office of Building Energy Research and Development, Building Systems Division of the U.S. Department of Energy under Contract No. DE-AC03-76Sr00098, and by the Bonneville Puwer Administration (Philip W. Thor, project manager), P.0. Box 3621, Portland, Oregon, 97208. 


\section{APPENDIX A - HEALTH STANDARDS AND GUIDELINES}

Tables A-1 through A-4 list a number of air quality standards. Table i-l fllustrates specfalized radon standards, Table $A-2$ rescimmended and promulgated formaldehyde standards, Table A-3 U.S. outdoor afr quality standards and Table A-4 U.S. Occuparional s indards. 
Table A-1. Radon Standards

Average Anmual

Indoor:

United States :

S1tes contaminanted

0.015

Cost-benefit analysis

by uranium-processrequired when level is

$1 \mathrm{ng}$ only slightly above anaximum

Interim and proposed cleanup standard for bufldings contaninanted by uraniumprocessing sites

Phosphate land, Florida:

Existing housing

$<0.02$

$>0.02$

Nlornal Ind oor background

Canada:

$>0.01$

$>0.02$

$>0.15$

Investigate

Primary action criterion Policy statement by AFCB Prompt action

Reduce to as low as reasonably achievable

Action Indicated

Recommendation to governor of Florida

Proposed standard

MSnA standard

\footnotetext{
The actual 11 m1ts are given in terms of "equivalent equilibriun concentracion" and are $200 \mathrm{~Bq} / \mathrm{m}^{3}$ and $70 \mathrm{~Bq} / \mathrm{m}^{3}$, respectively.

bperiod is a calendar year. Dose for any month is defined as cismulative dose $1 \mathrm{n}$ WL-is $\mathrm{d} 1 \mathrm{v}$ ided by 173 . Assuming $173 \mathrm{~h}$ worked per month (1.e., 2,076 h/yr), ayeras annual working level is $1 / 3 \mathrm{~kL}$.
} 
Level

$\left(0.1 \mathrm{ppu}=120 \mu \mathrm{g} / \mathrm{m}^{3}\right) \quad$ Status $\quad$ Ref.

AIBIEIT AIP.

II.s.

0.1 ppm max

Recommended by AIIIA

IIIDOOR AIR

U.

$\begin{array}{ll}\text { California } & 0.2 \mathrm{ppm} \\ \text { Minnesota } & 0.5 \mathrm{ppm} \\ \text { Wisconsin } & 0.4 \mathrm{p} \mathrm{pm} \\ & 0.2 \mathrm{p} \mathrm{pm}\end{array}$

Proposed 2

Proposed emergency standard 3

Proposed ef fective 05/1/80 4

Proposed effective $05 / 1 / 8$ i 4

Denmark

$0.12 \mathrm{ppm} \max$

Recommended

letherlands

$0.1 \mathrm{ppm} \max$

Recommended by Itinisters of

6

Housing and Health

Sweden

$0.1 \mathrm{ppm}$ max, new bulldings

$0.4 \mathrm{ppm} \mathrm{min}$, old buildings (a)

Proposed by the

$0.7 \mathrm{ppm}$ max, old bufldings (a)

Ilational Board of Health and Welfare

Federal Pepublic

of Cermany 0.1 Ppn max

Recommended by the

IInistry of Mealth

OCCUPATIOHAL AIR

$\underline{U} \cdot \underline{S}$.

3 рри, 8 hr time-welghted average

$5 \mathrm{ppm}$, ceiling

2 ppI, threshold limit value

$1 \mathrm{ppm}, 30$ minute max

Promulgated by OSHA

Promulgated by OSHA

Recommended by ACCIII

Recommended by IIOSH

\section{References}

1. American Industrial Hygiene Association, "Community Afr Quality Culdes, Aldehydes," Am. Ind. Hyg. Assoc. J., 29:606 (1968).

2. State of California, Assembly Bill Ho. 2586, as amended in Assembly Apr $t 116,1980$. 
3. Hews release from the linnesota Department of llealth, lay 22, 1980.

4. State of W1scons1n, Department of Labor and Human Relations, Safety and Bulldings Division. Proposed Formaldehyde Rule, W1s. Adm. Code, November 1979. (Hot enacted as of July 11, 1980).

5. I. Andersen, "Formaldehyde 1 n the Indoor Environment - Health Impl1cations and Setting of Standards," paper presented at the Indoor Climate Symposium, Copenhagen, Denmark, August 30-September 2, 1978.

6. R. Baars, "The Formal Aspects of the Formaldehyde Problem in the letherlands," paper presented at the "International Indoor Cl1mate Symposium," Copenhagen, Denmark, August 30-September 2, 1978.

7. H. Wahren, "Formaldehyde Indoor Air Standards in Sweden," paper presented at the CPSC Technical Workshop on Formaldehyde, Washington, D.C., Apr11 9-11, 1980.

8. Dr. Bernd Selfert, Institut fur Wasser-, Boden- und Lufthygiene des Bundesgesundheitsamtes, Berlin, Cermany, private communication, May, 1978 .

9. U.S. Occupational Safety and Health Administration, Occupational Safety and Ilealth Standards, Hazardous laterlals, 29 CFR 1910.1000, July $1,1979$.

10. "TLVs - Threshold Ifmit Values for Ctemical Substances and Physical Agents in the Workroom Environment with Intended Changes for 1977," American Conference of Governmental Industrial Hyglenists, P.0. Bor 1937, Cincinnat1, oll 45201 (1977).

11. National Institute for Occupational Safety and Ilealth, Criteria for a Recommended Standard...Occupational Fxposure to Formaldehyde, IIIoSIl Publication 11o. 77-126 (December, 1976).

llote

(a) 0.4 to $0.7 \mathrm{ppm}$ is a border area. Levels higher than $0.7 \mathrm{ppm}$ do not meet the standard. Levels lower than $0.4 \mathrm{ppm}$ do meet the standard. Levels within the border area do not meet the standard if the dvel1ers compla1n. In recently bullt houses, $0.7 \mathrm{pm}$ should be acceptable during the first six months. 
Table A-3. Nlational Primary Ambient-Air Quality Standards as Set by the U.S. Fnvironmental Protection Agency

\begin{tabular}{|c|c|c|c|c|}
\hline \multirow[b]{2}{*}{ Contami nant } & \multicolumn{2}{|c|}{ Long Term } & \multicolumn{2}{|c|}{ Short Term } \\
\hline & $\begin{array}{c}\text { Concentration, } \\
\mu \mathrm{g}\end{array}$ & $\begin{array}{c}\text { Averaging } \\
\text { Time }\end{array}$ & $\begin{array}{c}\text { Concentration, } \\
\mu \mathrm{g} / \mathrm{m}^{3}\end{array}$ & $\begin{array}{c}\text { Averaging } \\
\text { Time }\end{array}$ \\
\hline $\begin{array}{l}\text { Sulfur oxides, } \\
\text { measured as } \\
\text { Sulfur dioxide }\end{array}$ & 80 & $1 \mathrm{yr}$ & $365^{a}$ & $24 \mathrm{~h}$ \\
\hline $\begin{array}{l}\text { Particulate } \\
\text { matter }\end{array}$ & $75^{b}$ & $1 \mathrm{yr}$ & $260^{\mathrm{a}}$ & $24 \mathrm{~h}$ \\
\hline Carbon monoxide & - & - & $\begin{array}{l}10,000^{a} \\
40,000^{a}\end{array}$ & $\begin{array}{ll}8 \mathrm{~h} \\
1 \mathrm{~h}\end{array}$ \\
\hline Ozone & -- & - & $235^{c}$ & $1 \mathrm{~h}$ \\
\hline Ilydroca rbons & -- & -- & 160 & $3 h^{d}$ \\
\hline Mtrogen dioxide & 100 & 1 yr & - & -- \\
\hline Lead & 1.5 & 3 no $^{e}$ & - & $\rightarrow$ \\
\hline
\end{tabular}

alay be exceeded only once per year.

beometric mean.

${ }^{\mathrm{c}} \mathrm{Standard}$ is attained when expected number of days per calendar year with maximal hourly average concentrations above $0.12 \mathrm{ppm}$ ( $235 \mu \mathrm{g} / \mathrm{m}^{3}$ ) is equal to or less than 1 , as determined by Appendlx il to subchapter C, 40 CFR 50 .

$d_{3-h}$ period is $6 \mathrm{a} \cdot \mathrm{m}$. to $9 \mathrm{a} \cdot \mathrm{m}$.

$e_{3-m o}$ period is a calendar quarter. 
Table A-4. Selected Occupational-Safety and -Health Standards as Set by U.S. Occupational Safety and Ilealth Administration

\begin{tabular}{|c|c|c|}
\hline \multirow[b]{2}{*}{ Contaminant } & \multicolumn{2}{|c|}{ Concentration, b } \\
\hline & $\mathrm{ppm}$ & $\mathrm{mg} / \mathrm{m}^{3}$ \\
\hline Carbon dloxide & 5,000 & 9,000 \\
\hline Carbon monoxfde & 50 & 55 \\
\hline Forma I de hyde & 3 & 3.6 \\
\hline IItric oxide & 25 & 30 \\
\hline llterogen dioxtde & 5 & 9 \\
\hline Ozone & 0.1 & 0.2 \\
\hline Sulfur d1oxlde & 5 & 13 \\
\hline $\begin{array}{l}\text { Inert or nufsance } \\
\text { dust, respirable } \\
\text { fraction }\end{array}$ & $\rightarrow$ & 5 \\
\hline Asbestos & c & c \\
\hline
\end{tabular}

ata from 29 CFR 1910.1000 , Occupational Safety and Health Administration, July, 1979.

$b_{8-h}$ time-wefghted ave rages, except values for nitrogen dioxidr, which are celling values.

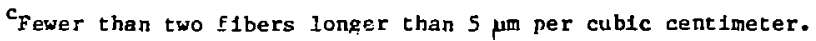


APPENDIX B - A MODEL FOR ESTIRATIIC MTE EFFECT OF COITROL TECHNIQUES

An equation describing the mass balance for a pollutant can sometimes be utilized to estimate the fmpact of control techniques on indoor pollutant levels. The mass balance equations presented below are similar to equations commonly used for indoor alr quality modeling (see for example reference 20); however, the equations have been iffied to Incorporate the effects of Indoor air quality control techniques. The equations are essentially unverified and are based upon a number of simplifying assumptions, Including the assumption of perfect mixing of the indoor air. The initial equation for pollutant mass balance is:

$$
\frac{d C_{1}}{d t}=(1-F) \frac{s}{v}+\left(p_{1} a_{1}+p_{2} a_{2}\right) C_{0}-\left(a_{1}+a_{2}+K+7 q\right) C_{1}
$$

whete:

$$
\begin{aligned}
C_{1}= & \text { Indoor pollutant concentration } \\
t= & \text { tIme variable } \\
F= & \begin{array}{l}
\text { correction factor for effect of control technique on pollutant } \\
\text { source strength }
\end{array}
\end{aligned}
$$

$S$ a pollutant source strength (1.e., rate a lich pollutant enters the indoor air) before control measure is implemented

$V$ - house volume

$P_{1}$ - fraction of outdoor pollutant that penetrates building shell

$a_{1}$ - air change rate for ventilation alr that enters through the building envilope

$P_{2}$ fraction of outdoor pollutant that penetrates mechanical ventilation system

$a_{2}=$ air change rate for ventilation air that enters through mechanical ventilation system

$C_{0}=$ outdoor pollutant concentration

$K$ = rate of pollutant removal by interaction with indoor surfaces

- efficiency of air cleaning device (1.e., unity minus the autlet pollutant concentration $/ C_{1}$ )

$Q$ - alr change rate for air passing through an air cleaning device

Assuming an Initial concentration $C_{f}(0)$ and assuming that all parameters except $C_{1}$ are constant over the time perfod of Interest yields the following equation for $C_{1}(t)$ : 


$$
\begin{gathered}
C_{1}(t)=\frac{\left(P_{1} a_{1}+P_{2} a_{2}\right) C_{0}+(1-F) s / V}{\left(a_{1}+a_{2}+K+\eta Q\right)}\left[1-e^{-\left(a_{1}+a_{2}+K+\eta Q\right) t}\right] \\
+C_{1}(0) e^{-\left(a_{1}+a_{2}+K+7 Q\right) t}
\end{gathered}
$$

If no Indoor alr quality controi technioues have been employed, the Indoor pollutant concentration $C_{1}$ is obtained by setting $a_{2}, F$, and $Q$. equal to zero with the following reault:

$$
\left.\dot{c}_{1}(t)=\frac{P_{1} a_{1} c_{0}+s / v}{a_{1}+k}\left[1-e^{-\left(a_{1}+K\right) t}\right]+c_{1}(0) e^{-\left(a_{1}\right.}+K\right) t
$$

The 1mpact of a control teshnique could be assessed by comparing $c_{1}(t)$ from equation 2 and $\dot{c}_{1}(t)$ from equation 3 , if values for all parameters in the equations were known. Little $=-\bar{i}$ 1s avallable to predict val $2: B$ for $F$ with accuracy. Traynor $X_{\text {. }}$ and $P_{1}$;3 coppustion products based ursa experiments in a chamber, Nero et ai. 33,41 present data on $S$ for radon ( $R$ equals zero and $P_{1}$ and $\mathrm{P}_{2}$ equal one for radon but not for radon daughters), and some data $1 \mathrm{fs}^{\mathrm{s}}$
avallable for evaiuation of $S$ for formaldehyde from particleboerd As the present time we have only limited data on values for these parameters, however, and measurements are required to determine values for air change rate $\left(a_{1}\right)$. In addition, operation of a mechanical ventilation oystem can cause a change in the Infiltration rate $\left(a_{1}\right)$ unless the mechanical ventflation system exhausts and supplies equal amounts of air. Therefore, this usefulness of equations 2 and 3 for accurately predicting pollutant concentrations and the effect of control measures fs IImited at this time; however, the equations do Indicate the relation between varlables and indicate the need for further experimental data.

If we make further simplifying assumptions, the equations become more usable but less accurate. Asguming that the Indoor concentration 1s steady with respect to time, and also assuming the outdoor concentration is much less than the indoor concentration yields the following equation for the ratio of $c_{1}$ to $\dot{c}_{1}$.

$$
\frac{c_{1}}{c_{1}}=a_{1}+\frac{(1-F)\left(a_{1}+k\right)}{a_{2}+R+B Q}
$$

Equation 4 shows that chanical ventilation will have a smaller beneficlal effect if the pollutant 18 reactive (1.e., $K \neq 0$ ). If the pollutant 1s non reactive $(K-0)$, no alr cleaning process is utilized $(Q=0)$, and 1 if the pollutant source otrength is unaffected by control measures $(F=0)$, then $C_{1} / \dot{c}_{1}=a_{1} /\left(a_{1}+a_{2}\right) 1$.e., the rat10 of pollutant concentrations equals the inverse $p$ the ratio of total air exchange rates. Desplte its simplicity, equation 4 should be useful for estimatIng the 1mpact of a control meagure in many situations. 
ADDENDUM - FORMULATION OF PRESENT CRITERIA FOR INCLUSION OF INFILTRATION-REDUCTION MEASURES IN THE REGIOHAL WEATHERIZATION PROGRAM

prepared by Don Wolfe, Bonneville Power Administration

When BPA began preparing its proposal for a reglonwide weacherization program in early 1981, the impacts of prospective programs were evaluated in accordence with the requi rements of the National Environmental Polfcy Act and the regulations of the Council on Environmental Quality (CEQ).

These regulations require that if the proposed action is determined to have significant Impacts on the quality of the human environment, an environmental 1mpact statement (EIS) must be prepared before the action can proceed, and if the significance of the Impacts is uncertain, an envi ronmenta! assessment (EA) must be prepared (40 CFR 1501.3, 1501.4). Research on the 1mpacts of the program 1ndicated that potentially significant Impacts could result from the program due to reduced alr exchange In residences, which would lead to increased concentrations of indoor air pollutants and Increased Impacts of those pollutants on the health of residents. Th1s research formed the basis for an $E A$ on the proposed program.

Significance is defined in the regulations by a number of consideratlons, Including long-term effects ( $40 \mathrm{CFP}$ 1508.27(a)), the degree to which the proposed action af fects the public health and safety (40 CFR $1505.27(b)(2))$, the degree to which the effects on the quality of the human envircnment are likely to be highly controversial (40 CFR 1508.27(b)(4)), the degree to which the possible effects on the human environment are highly uncertaln or Involve unlque or unknown risks ( 40 CFR $1508.27(b)(5))$, and whether it is reasonable to anticlpate a cumulatively significant Impact ( 40 CFR 1508.27(b)(7)).

Analysis of the program as initially proposed suggested that 1mpacts could be significant in part because omall increases in the exposure of Individuals to Indoor radon could contribute to long-term mortality over the population to be reached by the program due to Iung cancer. Exposure to other notentially carcinogenic pollutants, spesifically formaldehyde and benzo(a)pyrene, would also increase. These Imnacts appeared to be significant because of their long-term, cumulative effect on the public health. Their potential significance was reinforced jy the growing controversy about indoor air quality, the 1mportant urknowns about source strengths and health effects, and the atsence of rellable information on a number of aspects of the problem.

Analysis of the EA on the program led to the conclusion that the impacts of the proposal as initially designed were significant. AccordIng to the regulatious, an EIS would have to be completed before program Implementation could begin. Preparation of an $x$ IS would have required delaying program implementation and resulting energy savings by more than a year. However, an alternative approach would permit a finding of 
no algnificant Impact (FONSI) for the program so that implementation could proceed without delay for the completion of an EIS. As explained by the CEO in the Federal Register, sn agency may make a FONSI if, with mitigation, the effects of the proposal can be reduced to less than significant levels (46 FR 18038). By modifying the proposal so that signiflcant Impacts would be avolded, a FONSI for the program could be supported and the program could proceed withour waiting for the completion of an EIS.

In 11ght of the potential 1mpacts 1dentifled, the proposal was modified to include monitoring, mitigation measures, and research on indoor alr pollution to develop better information and to determine the extent of 1mpacts and the need for mitigation. These modifications were intended to permit a FONSI on the program so that Implementation could proceed without the need to prepare an EIS, and were published in the EA on the program.

In ascordance with the regulations $(40 \mathrm{CFR} 1501.4(\mathrm{~d})(2)(1))$, the EA and a draft FONSI for the program were made avallable for fi,blic review before BPA made a final deterwination whether to prepare an EIS. Comments from utilities and the public in review of the EA questioned whether the document adequately supported a FONSI for the modified program. The principal concerns expressed were the following:

1. There was not sufficlent eyldence that the mitigation measures provided would be effective enough to avold sigaificant impacts from the program.

2. The program as proposed could not guarantee that mitigation measures, even if shown to be effective, would be applied so as to avold significant impacts. For example, air-to-air heat exchangers might be disconnected tf residents disliked the nolse of their operation.

3. Even if mitigation measures could be assured to avold significant Impacts, thelr effects on program costs, cost-effectiveness, and energy savings were not known, thus it could not be demonstrated that such measures could be justifled in terms of program financing.

W1thour. considerable research, these concerns could not be answered In the EA, so the proposed program, even as modifled, could not go forwrard kased on a FONSI. However, the delay necessary for the preparation of an EIS was still not acceptable in achleving BPA's energy conservation goals, so the program was rodifled a second time. This time, Instead of proceeding with complete weatherization and atcempting to mitigate any adverse effects after the fact, the program was changed so that the potential adverse effects would not occur in the first place. This was accomplished by limiting the weatherization measures offered to those which would not reduce ventilation, except in cases where the major sources of indoor air pollutants were absent. In addition, all participants in the program were to be provided with brochures including Information about Indoor air pollution, the effect of weatherization on Indoor alr quality, and actlons which homeowners can take to reduce Indoor atr pollution. These provisions, along with the conservativeness of the asaessment of potential impacts, which would tend to overestimate 
rather than underestimate them, were the basis for a Folsi on the progr:am under which Implementation was permitted to proceed.

Homes in which the major sources of indoor air pollution were absent were defined by five chtracteristics. These were the following:

1. A full crawl space with cross ventilation (as per the Uniform ButldIng (ode), with a ground cover vapor barrier and floor insulation with a vapor barrier, which may be provided under the program;

2. No woodstoves or unvented combustion appliances, such as gas stoves or kerosene heaters;

3. A municipal water supply or surface water source for domestic supply;

4. Wood frame construction; and

5. No foam insulation.

In addition, alr-infiltration-reducling measures would not be offered for mobile homes weatherized under the program. These restrictions 1imited the avallability of complete weatherization to about 30 percent of the reglon's homes.

On several occasions, BPA has made assurances that the restricted measures would be offered to a greater percentage of participating homes as Improved Information provided assurance that no significant Impacts would result. As the foregoing discussion shows, however, any changes In the avallability of measures must be supported by an analysis of impacts which clearly demonstrates that no significant impacts will result.

The paper describes an approach for extending the avallability of the measures restricted under the program. 